\title{
Mobility of Organic
Complexes of Nickel and \\ Mobility of Organic
Complexes of Nickel and Cobalt in Soils
}

\author{
J. L. Swanson
}

September 1983

Prepared for the U.S. Department of Energy under Contract DE-AC06-76RLO 1830

Pacific Northwest Laboratory Operated for the U.S. Department of Energy by Battelle Memorial Institute

(1)

( 


\section{DISCLAIMER}

This report was prepared as an account of work sponsored by an agency of the United States Government. Neither the United States Government nor any agency thereof, nor any of their employees, makes any warranty, express or implied, or assumes any legal liability or responsibility for the accuracy, completeness, or usefulness of any information, apparatus, product, or process disclosed, or represents that its use would not infringe privately owned rights. Reference herein to any specific commercial product, process, or service by trade name, trademark, manufacturer, or otherwise, does not necessarily constitute or imply its endorsement, recommendation, or favoring by the United States Government or any agency thereof. The views and opinions of authors expressed herein do not necessarily state or reflect those of the United States Government or any agency thereof.

\section{PACIFIC NORTHWEST LABORATORY}

operated by

BATTELLE

for the

UNITED STATES DEPARTMENT OF ENERGY

under Contract DE-AC06-76RLO 1830

Printed in the United States of America Available from

National Technical Information Service United States Department of Commerce 5285 Port Royal Road Springfield, Virginia 22161

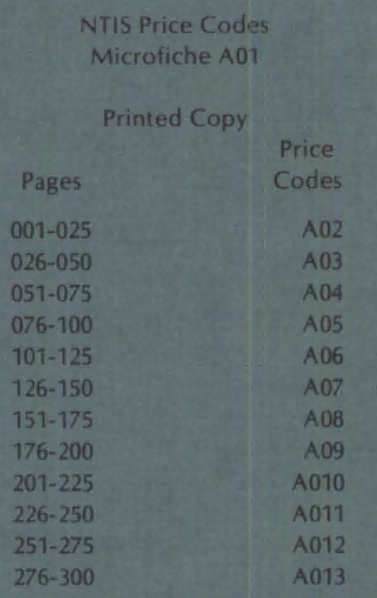




\section{6}

PNL -4796

UC $-70 B$

MOBILITY OF ORGANIC COMPLEXES

OF NICKEL AND COBALT IN SOILS

J. L. Swanson

September 1983

Prepared for the U.S. Department of Energy under Contract DE-ACO6-76RLO 1830

Pacific Northwest Laboratory Richland, Washington 99352 
$\because$ 


\section{$\underline{\text { SUMMARY }}$}

This is the third and final report on a study of the effect of organic complexing agents on the behavior of low-level waste radionuclides in soil/groundwater systems. The objective of this project has been to develop and employ standard procedures for evaluating how and to what extent organic complexants affect the sorption of low-level waste radionuclides by soils. A high sorption is desired to minimize the chance that dangerous quantities of radionuclides would migrate from the disposal site to the accessible environment. This report summarizes some of the earlier findings and presents in more detail the results of the work done in FY 1983.

The major experimental procedure of this project involved batch contacts of solutions with soils with periodic analysis of the liquid phase. The solutions contained varying amounts of different organic complexing agents. Three different soils were studied. Work in FY 1983 again emphasized Co and $\mathrm{Ni}$, which have important isotopes present in low-level wastes. An important activity has been the development of procedures to determine whether a radionuclide sorption coefficient that appears to be stable with time is truty an equilibrium value or appears stable only because the rate of change is very slow. A knowledge of this is important to accurate prediction of the rate of radionuclide migration.

The effect of organic complexants on the sorption of radionuclides varies widely among different complexants. This variation involves not only the concentration of complexant required to have an appreciable effect on the equilibrium sorption coefficient, but also how rapidly the equilibrium is attained. The latter factor is more important since, in the extreme case, kinetically inert complexes could migrate at the same speed as the groundwater. Rapid dissociation of the complexes, so that the uncomplexed radionuclide can be sorbed by the soil, is desirable.

Work done in FY 1983 showed that sorption of some complexed radionuclides, as well as of uncomplexed ones, is important with some soils. Sorption of $\mathrm{Ni}$-EDTA and Co-EDTA complexes occurs with soils from Oak Ridge and Savannah River. The sorption of these kinetically inert complexes results in a lower radionuclide migration rate than if it did not occur; however, the 
migration rate is still greater than if the complexes were not kinetically inert, or if complexants were absent.

The comparison of complexing agents was also extended in FY 1983 to include additional individual agents and aiso some proprietary decontamination mixtures. These tests included study of the fate of some complexants themselves as well as study of their effects on radionuclide distribution. The results of these tests continue to indicate that all organic complexing agents should not be considered to be equally hazardous from a waste disposal standpoint.

Different soils affect organic complexant-enhanced radionuclide mobility differently. Some sorb kinetically inert complexes and some do not. Radionuclide complexes dissociate more rapidly in some soil/groundwater systems than they do in others. Soils also differ in their leaching by complexant solutions, which also affects radionuclide behavior. Data were obtained in this area during FY 1983.

Other site-specific factors, such as hydrologic ones, are very important to radionuclide migration and to the possible effects of organic complexation. There appear to be a number of combinations of site-specific and complexant-specific factors that can give radionuclide mobilities that are acceptably small even in the presence of complexants. 


\section{CONTENTS}

SUMMARY..................................................

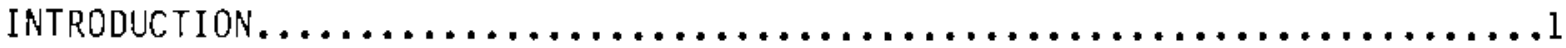

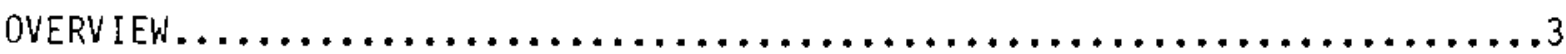

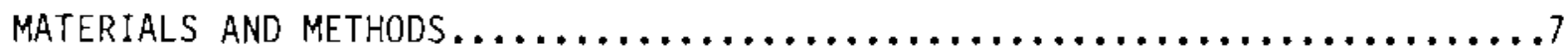

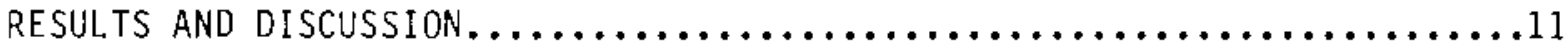

SORPTION OF EDTA COMPLEXES OF $\mathrm{Ni}$ and Co.........................

Ni -EDTA Complex Sorption..............................11

Co-EDTA Complex Sorption..............................21

Earlier Work on Complex Sorption........................25

COMPLEXANT DECOMPOSITION AND SORPTION........................26

Citrate Decomposition................................26

EDTA Decomposition and Sorption........................28

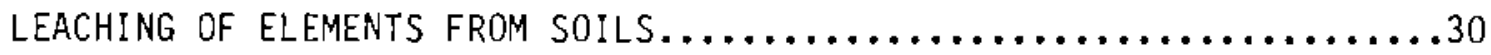

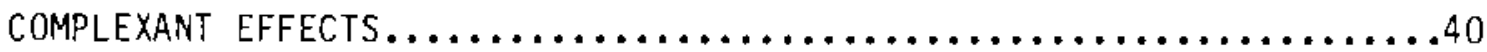

Commercial Decontamination Solutions......................40

Additional Complexants...............................42

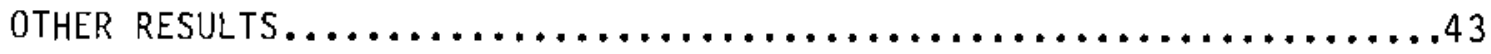

Difference in Soil Batches.............................43

$\mathrm{Ni} / \mathrm{NTA} /$ ak Ridge Soil System...........................46

Effect of pH on Ni/EDTA Complex Dissociation Rate.............48

$\mathrm{Ni} /$ EDTA/Hanford Soil System.............................50

Fe(III) Addition Experiments..........................50

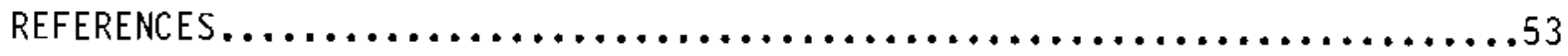

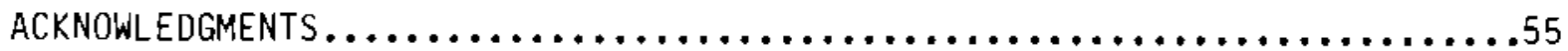

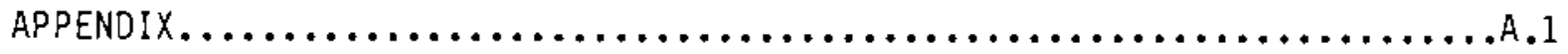


FIGURES

1 Evidence for Sorption of Ni -EDTA Complex by Oak Ridge Soil........12

2 Effect of EDTA Concentration on Pseudo-Equilibrium Sorption

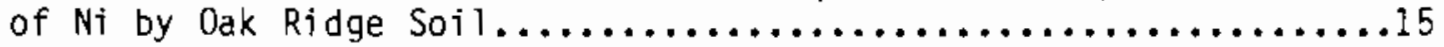

3 Additional Evidence for Sorption of Ni-EDTA Complex by 0 ak Ridge Soil...................................

4 Results of Precomplexed $\mathrm{Ni}$-EDTA Experiments with

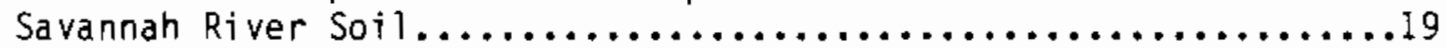

5 Comparison of Precomplexed and Presorbed Experiments from the Ni/EDTA/Savannah River Soil System.................20

6 Evidence for Sorption of Co-EDTA Complex by Oak Ridge

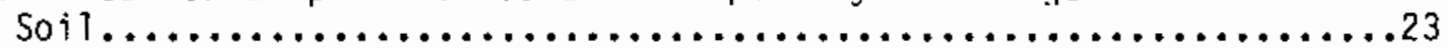

7 Disappearance of Citrate Under Experimental Conditions..........27

8 Apparent EDTA Stability Under Experimental Conditions............29

9 Apparent Sorption of EDTA by Oak Ridge Soil $\ldots \ldots \ldots \ldots \ldots \ldots \ldots \ldots$

10 Major Complex-Forming Elements Leached from Savannah River Soil at Two Different EOTA Concentrations.................

11 Major Complex-Forming Elements Leached from Oak Ridge Soil at Three Different EDTA Concentrations.....................

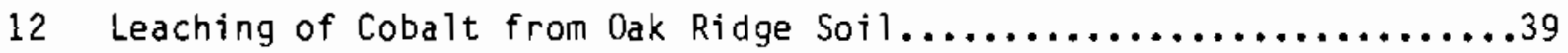

13 Sorption of Cobalt from Proprietary Decontamination Solutions..........................................

14 Comparison of Precomplexed and Presorbed Experiments ............44

15 Effect of Soil Batch from Co(II)/EDTA/Savannah River Soil System........................................... 45

16 Results from $\mathrm{Ni} / \mathrm{NTA} / 0$ ak Ridge Soil System at Three Different NTA Concentrations.........................47

17 Effect of $\mathrm{pH}$ on $\mathrm{Ni}$-EDTA Complex Dissociation Rate...............49 


\section{TABLES}

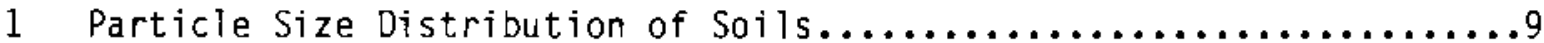

2 Pseudo-Equilibrium Data for Ni/EDTA/ORNL Soil System..............14

3 Summary of Test Results for the Co/EDTA/Oak Ridge Soil System...................................24

4 Complex-Forming Elements Leached from Soils......................

5 Properties of Soil-Derived Metal Ions..........................

6 Readily Leachable Quantities of Complex-

Forming Elements.................................. 
*

$\therefore$

, 
INTRODUCTION

Organic complexing agents are often used in the nuclear industry as decontamination agents to remove radioactive materials from contaminated equipment and facilities. The radioactive wastes resulting from such activities therefore contain the decontamination agents, unless they are destroyed before the wastes are disposed of. The potential effects of such complexing agents on the migration of radionuclides from waste disposal sites has been of concern for some time, especially since the report of the migration of a Co-EDTA complex from an Oak Ridge burial site (Means, Crerar, and Duguid 1978).

Pacific Northwest Laboratory (PNL) has been conducting a study of the effect of organic complexing agents on the behavior of low-level waste radionuclides in soil/groundwater systems for the U. S. Department of Energy's Low-Level Waste Management Program (LLWMP). This is the third and final report on the results of the project, whose objective has been to develop and emplay standard procedures for evaluating how and to what extent organic complexants affect the sorption of low-level waste radionuclides by soils. A high sorption is desired to minimize the chance that dangerous quantities of radionuclides would migrate from the disposal site to the accessible environment.

Earlier results (Swanson 1981 and 1982) have shown the importance of kinetically inert complexes to radionuclide migration. When the rate of complex dissociation is very slow and the complex itself is not sorbed by the soil, the mobility of precomplexed radionuclides will be much greater than that predicted from equilibrium considerations. In the extreme case, kinetically inert complexes would migrate at the same speed as the groundwater. Rapid dissociation of the complexes, so that the uncomplexed radionuclide can be sorbed by the soil, is desirable.

Different rates of dissociation of complexes of $\mathrm{Co}_{\mathrm{O}}$ and $\mathrm{Ni}$, two elements having isotopes present in low-level wastes, were observed with different complexants and different soils. Citrate and oxalate complexes were found to equilibrate more rapidly than EDTA and DTPA complexes. Thus, citrate and oxalate would be less likely to give appreciable enhancement of radionuclide mobility than EDTA and DTPA. More rapid equilibration of EDTA and DTPA 
compiexes was observed with Savannah River soil than with Hanford soil. Thus, there would be much less chance of kinetically inert complexes migrating at the same speed as the groundwater at Savannah River than at Hanford. The rate of groundwater flow is also very important to radionuclide migration, of course.

The highlights of the work during FY 1983, which is the subject of this report, inciude

- demonstration that EBTA complexes of $\mathrm{Ni}$ and Co are sorbed by some soils (Oak Ridge and Savannah River)

- comparison of the rates of complex dissociation with additional complexants (HEDTA, NTA, and proprietary decontamination solutions)

- study of the leaching of elements from the soil, and how this leaching can affect radionuclide behavior

- study of the decomposition and sorption of some complexants. 
OVERVIEW

The results discussed in the earlier reports (Swanson 1981 and 1982) and those to be discussed in a subsequent section contain examples of different effects of organic complexants on radionuclide mobility. In none of the cases studied was the radionuclide mobility decreased by the complexant. The complexant had little or no effect in some systems, but in most cases the effect was one of increased radionuclide mobility. However, great differences were observed in the magnitude of the enhanced mobility, and it is this magnitude which should be of prime concern. It makes no difference to public health and safety if the presence of a complexant increases the distance traveled by a radionuclide from $0.1 \mathrm{~m}$ to $10 \mathrm{~m}$, for example, if it must travel $1000 \mathrm{~m}$ to reach the accessible environment.

The magnitude of the enhanced radionuclide mobility resulting from the presence of a certain complexant depends not only on the magnitudes of the formation constants of the complexes with the radionuclides and the soilderived elements, but also on the rates of the complex formation and dissociation reactions and on the rate of groundwater movement. It also depends on whether the complexes themselves are sorbed by the soil.

The magnitude of the enhanced radionuclide mobility also varies widely among radionuclides, complexants, and soils. The radionuclides present in low-level wastes are largely defined by the normal operations of the nuclear industry. The organic complexants currently present in low-level wastes are largely defined by the current practices of the nuclear industry, but this is an area where changes could perhaps be made relatively simply; especially if some complexants were required to be destroyed or packaged more rigorously before the wastes could be disposed, while others could be disposed without special treatment. The kinds of soils present in low-level waste disposal sites will likely vary from site to site, and some soils are more tolerant of organic complexants than others.

Regardless of the relative magnitudes of organic complexant-enhanced radionuclide mobilities in soils from different sites, other site-specific data are also important. For instance, a site having soil which results in a large complexant-enhanced mobility could still be a preferred site if the 
groundwater flow is sufficiently low. A mobile species will not move unless there is water to transport it.

Desirable characteristics of the soil at a waste disposal site relative to the complexant-enhanced mobility of radionuclides include:

- high radionuclide sorption capability (Kd) and capacity (loading)

- large quantities of elements that form highly stable complexes with the complexants present in the waste

- presence of materials that result in rapid attainment of the various equilibria involving the complexants, the radionuclides, and the soilderived elements.

The most desirable characteristic of a complexant from a waste disposal standpoint is that it rapidly equilibrates with the radionucilides and the soil-derived elements. If all equilibria are attained rapidly, complexantenhanced mobility of radionuclides should be minimai because of a low free complexant concentration resulting from dilution by the groundwater and from competition for the complexants by the elements present in the soil. Radionuclide mobility could be much more severe in the case of kinetically inert complexes, which may migrate through some soils at the same speed as the groundwater or which may be sorbed by other soils in a pseudo-equilibrium situation.

Another desirable characteristic of the complexants is that the constants for the formation of complexes with radionuclides not be too high; that is, a high free complexant concentration would be required to lower the kd value to an unacceptable level. Still another desirable characteristic is instability under environmental conditions, especially if the complexant degrades to materials that are not complexants themselves.

An ideal low-level waste disposal site would be one from which there is absolutely no migration of water; there could thus be no migration of radionuclides regardless of the presence of organic complexants. This is not practically achievable in the real world. However, it is thought to be likely that there are a number of combinations of site-specific and complexantspecific factors such as those discussed above which, in conjunction with the water migration rate, will give radionuclide mobilities that are acceptably 
small even in the presence of complexants. The work done on this project helps to identify such satisfactory combinations of factors. 

MATERIALS AND METHODS

As in the earlier work (Swanson 1981 and 1982), the major experimental procedure this year was a batch contact of solution and soil at room temperature, with periodic analysis of portions of the liquid phase for the component of interest. This procedure allows data to be obtained in one type of experiment on both the equilibrium position resulting from the presence of complexant, and the rate at which that position is attained. Prior to analysis, the suspensions were first centrifuged to obtain a gross phase separation and portions of the liquid phase were then filtered through a $2-n m$ uitrafiltration membrane cone to remove finely divided solids. Unless stated otherwise, all experiments were done while exposed to air.

Proof of radionuclide distribution equitibrium was a prime concern and the "second contact" and the "both directions" methods were again used to allow determination of whether a condition that appears to be stable with time is truly an equilibrium condition or appears stable only because the rate of change is very slow. A knowledge of this is important to accurate prediction of the rate of radionuclide migration.

In the "second contact" method, a portion of the solution is removed from a suspension that appears to be stable with time and is then contacted with a fresh portion of soil. If the radionuclide distribution coefficient in the second contact is not essentially the same as in the first contact, it is a good indication that a true equilibrium condition is not being measured. The mechanics of this method involved centrifugation of the suspension and transfer of a portion of the partially clarified solution to an empty tube, where it was mixed and sampled to determine the total amount (in solution plus as finely divided solids) of radionuclide transferred before the second portion of soil was added and the second contact was begun. Comparison of the analysis of the partially clarified solution with analysis of the final filtrate of the first contact indicated that the amount of radionuclide that was associated with finely divided solid was generally small.

In the "both directions" method, two experiments are performed under a given set of conditions except that in one case the radionuclide and complexing agent are mixed (to allow the complex to form) before exposure to the soil and in the other case the radionuclide is sorbed by the soil before 
the complexing agent is added. We speak of the former case as a precomplexedtype experiment and the latter case as a presorbed-type experiment. Unless the same radionuclide distribution coefficient is obtained in both experiments under the given set of conditions, a true equilibrium position is not being measured.

Results obtained this year necessitated an additional refinement to these methods. This type of experiment, termed a presorbed (complexed) experiment, involves separating the soil (and sorbed radionuclide) from a precomplexedtype experiment and then contacting it with a fresh portion of complexant solution. It is the same as a normal presorbed-type experiment except that in this case the radionuclide is sorbed from a solution containing complexant, while in the normal case it is sorbed in the absence of complexants. In actual practice, the presorbed-type experiment suspension was centrifuged, most (but not al1) of the centrate was removed, and fresh complexant solution was then added. The total solution volume and the total radionuclide inventory were obtained by subtracting the quantities that were periodically removed for analysis from the quantities initially present in the precomplexed-type experiment.

Most of the experimental results with radionuclides are expressed as percent of the initial radionuclide concentration remaining in solution. Radionuclide distribution coefficients (apparent $\mathrm{Kd}$ ) are also used in some cases. The apparent $k d$ is defined as the quantity of material per gram of soil divided by the quantity of material per milliliter of solution, and is derived from the fraction of the material present in solution and the soil-tosolution ratio as follows:

$$
\text { Apparent } K d=\frac{1-(\text { fraction in solution })}{\text { (fraction in solution) }} \times \frac{1}{(g \text { soil)/(mL solution) }} \text {. }
$$

The radionuclide behaviors were followed by beta counting $63_{\mathrm{Ni}}$ and gamma counting ${ }^{60} \mathrm{Co}$. Standards were counted with each set of samples so that corrections could be made for the minor variations in counting efficiency that occurred. Total $\mathrm{Ni}$ and $\mathrm{Co}$ concentrations were calculated from data provided by the supplier of the tracers.

The behavior of complexants was followed by beta counting with ${ }^{14} \mathrm{C}$ labeled complexants, using citric acid labeled in the end carboxyl carbon 
atoms and EDTA labeled in the carbon atoms adjacent to the carboxyl groups. These samples were acidified and stirred for 10 min to drive off any $\mathrm{CO}_{2}$ that formed by complexant degradation. Citrate was also determined in several cases using ion chromatography, and gas chromatography following methylation was used to determine EDTA in a few cases.

Concentrations of metal ions leached from soils into complexant solutions were determined by emission spectroscopy using an inductively coupled plasma (ICP) for excitation. The instrument was set to automatically analyze for the following elements: $\mathrm{Al}$, As, B, Ba, $\mathrm{Ca}, \mathrm{Cd}, \mathrm{Ce}, \mathrm{Co}, \mathrm{Cr}, \mathrm{Cu}, \mathrm{Fe}, \mathrm{K}, \mathrm{Li}, \mathrm{Mg}, \mathrm{Mn}$, Mo, Na, Ni, P, Pb, Ru, Sb, Si, Sr, Te, Ti, Zn, Zr, and several rare earths. Many of these elements are not of importance to this project; the 1 ist was set by the desires of major users of the instrument.

The study was expanded this year to include a sample of soil from a waste burial site at the 0ak Ridge National Laboratory. This soil was air-dried at room temperature for 1 week and sieved before use. Its particle size distribution is compared in Table 1 with those of the Hanford and Savannah River soil samples. The soils generally used in the experiments were from the 150 to $500 \mu m$ size fractions. Most of the work done this year with Savannah River soil used material from the second batch, while soil from the first batch was used last year.

TABLE 1. Particle Size Distribution of Soils

Soil Source

Hanford (a)

Savannah River-1 (b)

Savannah River-2

Oak Ridge (c) wt\% in Indicated Size Fraction

\begin{tabular}{|c|c|c|c|}
\hline 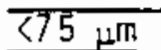 & $75-150 \mu \mathrm{m}$ & $150-500 \mu \mathrm{m}$ & $>500 \mu \pi$ \\
\hline
\end{tabular}

4.9

5.6

44.8

44.7

3.2

5.5

33.3

58.0

4.7

6.5

41.0

$47 . B$

32.2

19.7

32.2

(a) Hanford A, as described by Gee and Campbell (1980).

(b) Samples I-17 \#1 and I-17 \#2, dated 2-11-82. Taken from near the surface inside the burial ground. Typical of soils used in lysimeter studies at Savannah River Laboratory.

(c) Sample from burial ground 6, dated 8-27-82. Descriptive data for similar soil from the same site are given by Vaughan et al. (1982). 

RESULTS AND DISCUSSION

Experimental results in a number of areas are presented and discussed here. Major topics include 1) sorption of EDTA complexes of $\mathrm{Ni}$ and $\mathrm{Co}, 2$ ) complexant decomposition and sorption, 3) leaching of elements from soils, 4) complexant effects, and 5) other results.

SORPTION OF EDTA COMPLEXES OF Ni AND CO

In the first report of this series (Swanson 1981), we described the effects of EDTA on the sorption of different elements by Hanford soil. With Cs and $\mathrm{Sr}$, no effect of EDTA was observed. With Eu, a rapid and reversible effect was observed that agreed with the concept that the effect of EDTA was to complex the metal ion and keep it in solution. With $\mathrm{Ni}$ and Co, the reactions were so slow that equilibrium was not attained. The next year's study (Swanson 1982) showed that more rapid equilibration occurred with Savannah River soil than with Hanford soil. The current work has included studies with Oak Ridge soil; these results indicate that the EDTA complexes of $\mathrm{Ni}$ and Co themselves are rapidly and reversibly sorbed by the soil and that a pseudo-equilibrium position is maintained for an appreciable period of time. Additional data with Savannah River soil indicate that a similar phenomenon occurs there, but that the pseudo-equilibrium position is not as stable.

There have been other reports of sorption of metal-ligand complexes by soils, some of which will be discussed later. In those studies, the prime evidence for sorption of the complex was that the $\mathrm{kd}$ was higher when the ligand was present. This is not the case with the results presented here; the Kd values in the presence of EDTA were lower than in its absence, but in a different pattern than results when the only effect of EDTA is to keep the radionuclide in solution. The evidence for the sorption of these Ni-EDTA and Co-EDTA complexes is thus somewhat subtle, and would not have been observed without the "proof of equilibrium" tests developed in the earlier work (Swanson 1981 and 1982).

Ni -EDTA Complex Sorption

Data illustrating the type of evidence that led to the conclusion that sorption of the complex itself was occurring are presented in Figure 1, where 


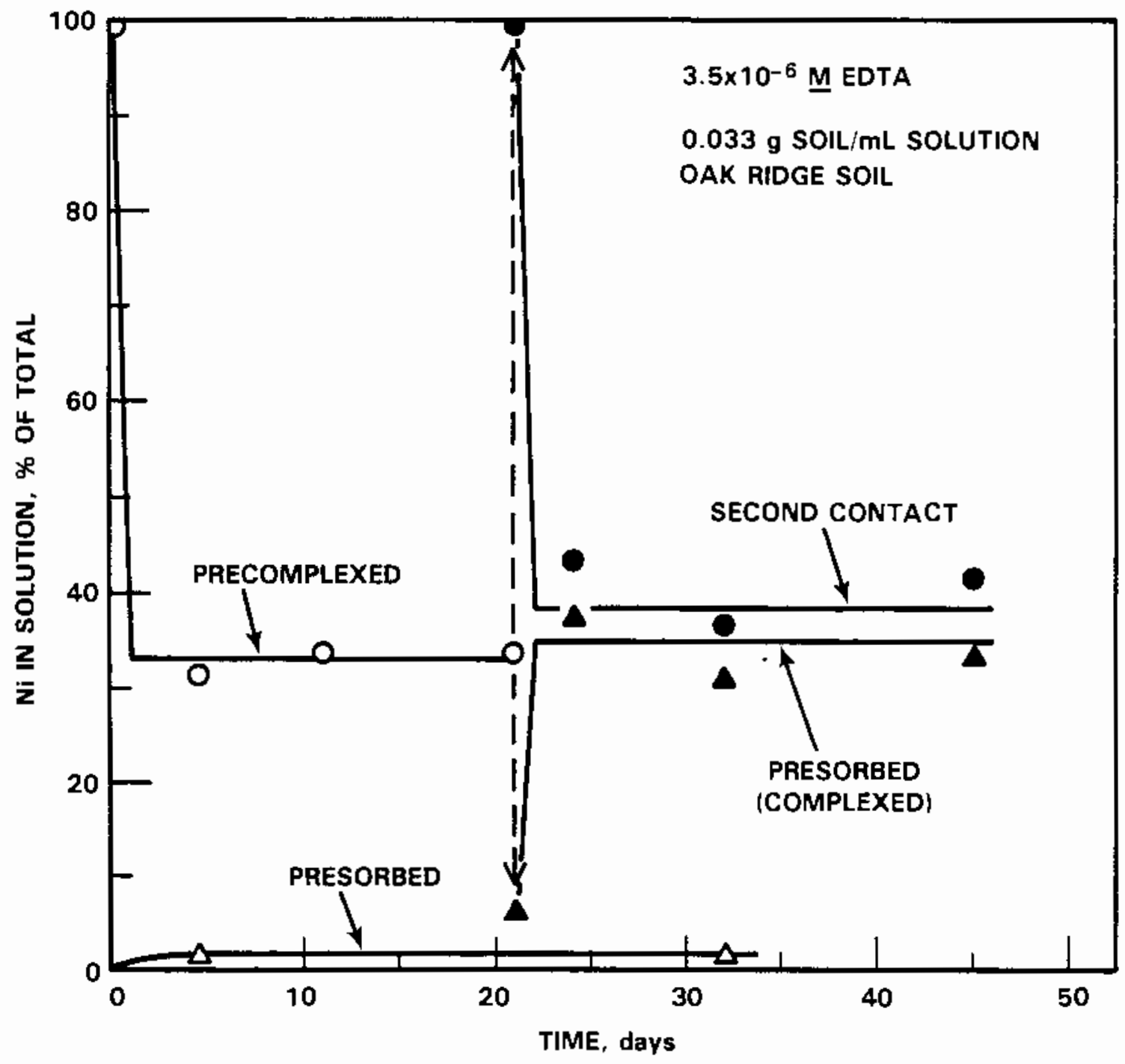

FIGURE 1. Evidence for Sorption of Ni-EDTA Complex by Oak Ridge Soil 
the percentage of $\mathrm{Ni}$ found in solution is plotted as a function of time for several experiments. All of these experiments contained $3.5 \times 10^{-6} \mathrm{M}$ EDTA and $5 \times 10^{-9} \mathrm{M} \mathrm{Ni}$, and involved contact with an 0ak Ridge soil at a soil-to-solution ratio of $0.033 \mathrm{~g} / \mathrm{mL}$.

In the precomplexed experiment (data denoted by open circles), the $\mathrm{Ni}$ EDTA solution was prepared and aged for 3 days before the soil was added to start the experiment. In this experiment a constant, steady state $\mathrm{Ni}$ concentration (corresponding to about 33\% of the initial Ni concentration) was attained rapidly. In the presorbed experiment (data denoted by open triangles), the $\mathrm{Ni}$ solution was contacted with the soil for 3 days before the EDTA was added to start the experiment. In this case, only about $1 \%$ of the Ni was found in solution after a month. Thus, the test for true equilibrium by approaching equilibrium from both directions failed because different results were obtained (in these time periods) from the two directions.

Another test of equilibrium that has been used effectively in the past (Swanson 1981 and 1982) is the "second-contact method," in which the solution is separated from the soil and contacted with a second portion of soil. If the same result is obtained in the two contacts, it is a good indication that an equilibrium position was attained in both contacts. This method was used on the solution from the precomplexed experiment after 21 days; the results of the second contact (the filled circles on Figure 1) were in good agreement with those of the first contact: about $38 \%$ of the $\mathrm{Ni}$ present in solution after the first contact remained in solution after the second contact. Thus, this test of equilibrium was positive. However, the fact that the result of the "both directions" test of equilibrium was negative meant that the question of true equitibrium was still not resolved.

The key procedure in resolving this question was to contact the soil (and a small portion of accompanying liquid) from the first precomplexed experiment with a fresh EDTA solution. This gives a situation similar to the first presorbed experiment (the open triangle data of Figure 1) except that in the first case the $\mathrm{Ni}$ was sorbed from a solution that contained no EDTA and in this second case the $\mathrm{Ni}$ was sorbed from a solution that did contain EDTA. This second type of presorption experiment, termed presorbed (complexed), gave markedly different results (the shaded triangles in Figure 1) than the first; about $35 \%$ of the $\mathrm{Ni}$ that had been on the soil rapidly entered the solution and 
remained at that level. It was thus concluded that the rapid desorption in the second case occurred because the sorbed Ni species was a Ni-EDTA complex, rather than an uncomplexed $\mathrm{Ni}$ species as was sorbed in the first case.

This sorption of a Ni-EDTA complex by Oak Ridge soil appears to be only a pseudo-equilibrium, rather than a true equilibrium, situation. At true equilibrium, the same result should be obtained whether or not the $\mathrm{Ni}$ is complexed before it is exposed to the soil. This pseudo-equilibrium has lasted for time periods of several months in this system. This is probably long enough to use the apparent $k d$ values for this pseudo-equilibrium position in modeling the migration of $\mathrm{Ni}$ in this system.

Data were also collected at other EDTA concentrations in the Ni/EDTA/Oak Ridge soil system. These data showed that the EDTA concentration had relatively little effect on the fraction of $\mathrm{Ni}$ remaining in solution when solutions containing the preformed complex were contacted with soil (Table 2 and Figure 2). This observation also tends to corroborate the conclusion that a complex species is being sorbed by the soil. In contrast, a strong dependence of distribution coefficient on complexant concentration results when the uncomplexed radionuclide is the sorbed species, as illustrated by the Eu/EDTA/Hanford soil systen data also presented in Figure 2. The markedly lower sorption of $\mathrm{Ni}$ measured at $1 \times 10^{-3} \mathrm{M}$ EDTA may mean that a more highly

TABLE 2. Pseudo-Equilibrium Data for Ni/EDTA/ORNL Soil System

\begin{tabular}{|c|c|c|c|c|}
\hline Tube & $\begin{array}{l}\text { Total EDTA } \\
\text { Added, M }\end{array}$ & $\mathrm{pH}$ & $\begin{array}{l}\text { Ni in Solutign, } \\
\text { \% of Total }\end{array}$ & $\begin{array}{l}\text { Apparent } \\
\mathrm{Kd}, \mathrm{mL} / \mathrm{g}\end{array}$ \\
\hline 682 & $1.0 \times 10^{-7}$ & & 22 & 120 \\
\hline 651 & $1.0 \times 10^{-6}$ & & 31 & 67 \\
\hline 643 & $3.5 \times 10^{-6}$ & & 33 & 61 \\
\hline 652 & $1.0 \times 10^{-5}$ & & 39 & 47 \\
\hline 653 & $3.5 \times 10^{-5}$ & & 46 & 35 \\
\hline 586 & $1.0 \times 10^{-4}$ & 5.9 & 57 & 23 \\
\hline 683 & $1.0 \times 10^{-3}$ & & 87 & 4.5 \\
\hline
\end{tabular}

(a) $0.033 \mathrm{~g} \mathrm{soil/mL} \mathrm{solution.}$ 


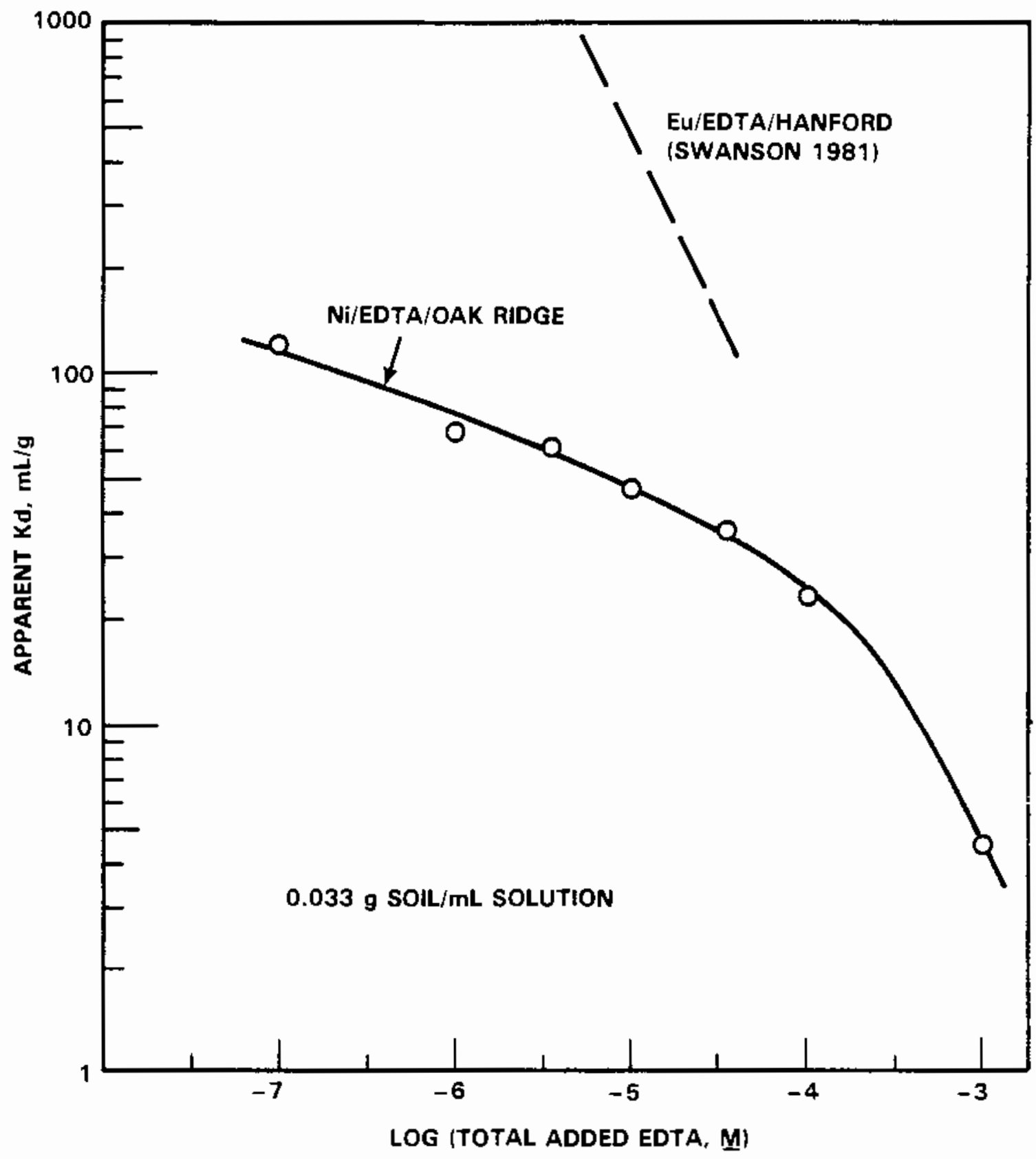

FIGURE 2. Effect of EDTA Concentration on Pseudo-Equilibrium Sorption of $\mathrm{Ni}$ by Oak Ridge Soil 
complexed (thus, less sorptive) species becomes more important at higher concentrations.

Another difference observed at the higher EDTA concentrations is that more presorbed (uncomplexed) $\mathrm{Ni}$ is removed from the soil by the EDTA solution. Figure 3 contains data obtained with $1 \times 10^{-4} \mathrm{M}$ EDTA in precomplexed, second contact, and presorbed (uncomplexed) experiments (precomplexation and presorption times of 3 days were used in these experiments, as before). The precomplexed and second contact experiments both indicate the rapid attainment of a pseudo-equilibrium position, as was the case at the lower EDTA concentration (Figure 1). However, the fraction of the presorbed (uncomplexed) $\mathrm{Ni}$ that is removed from the soil is appreciable at this high an EDTA concentration, and increases slowly with time. This shows that the behavior of $\mathrm{Ni}$ in this system depends less on whether the $\mathrm{Ni}$ is precomplexed or presorbed at high EDTA concentrations than it does at low EDTA concentrations.

Other evidence for the sorption of a $\mathrm{Ni}$-EDTA species by Oak Ridge soil was obtained in experiments using ${ }^{14} \mathrm{C}-1$ abeled EOTA. Two experiments were done with $1 \times 10^{-6} \mathrm{M}$ EDTA and $0.033 \mathrm{~g} / \mathrm{mL}$ of ORNL soil, one without $N i$ and one with $5 \times 10^{-7}$ M Ni. The concentration of EOTA found to remain in solution on contact with the soil was about $1.3 \times 10^{-7} \mathrm{M}$ Iower in the experiment containing $\mathrm{Ni}$, indicating that sorption of a $\mathrm{Ni}$-EDTA complex was indeed occurring. If this difference was due to the sorption of a 1:1 complex of $\mathrm{Ni}$-EDTA (and no other sorption of $\mathrm{Ni}$ occurred), then about $3.7 \times 10^{-7} \mathrm{M} \mathrm{Ni}$ remained in solution and the $\mathrm{Ni} K d$ was about $1 \mathrm{D}$ (compared to the value of nearly 100 expected for these conditions from the data of Table 2). It is necessary to assume sorption of a 3:1 complex of $\mathrm{Ni}$-EDTA to bring the two sets of data into conformance. However, the uncertainty resulting from a small difference between large numbers makes such a conclusion highly speculative.

The sorption of the Ni-EDTA complex by Oak Ridge soil retards the migration of the kinetically inert complex in pseudo-equilibrium with the soil; that is, the Ni will migrate less rapidly than if the complex were not sorbed by the soil (as is the case with Hanford soil). However, the Ni will still migrate more rapidly than if EDTA were absent. For example, the data from the presorbed experiment shown in Figure 1 allow estimation of apparent $\mathrm{Kd}>2 \times 10^{3}$ for uncomplexed $\mathrm{Ni}$; this value is much higher than those measured 


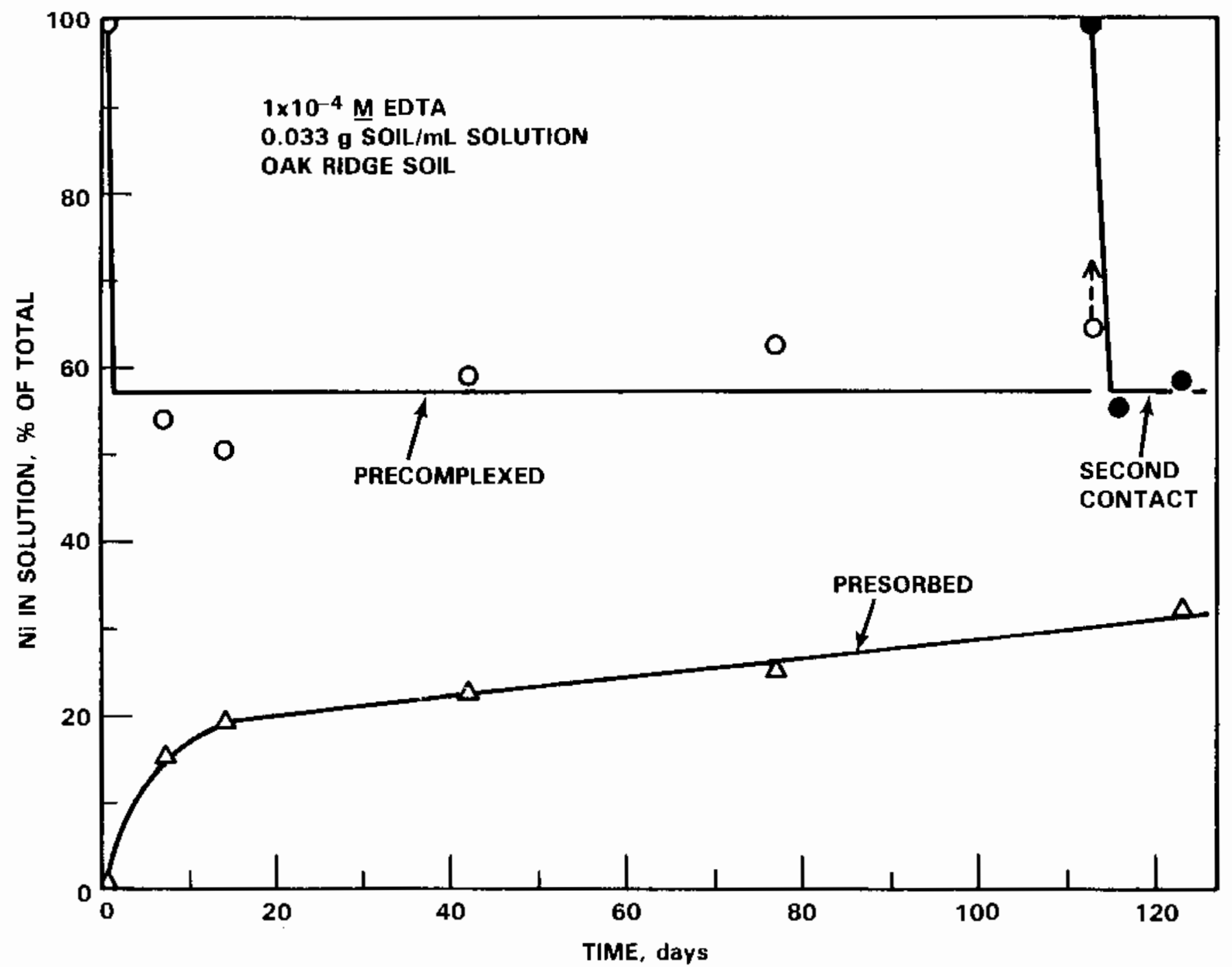

FIGURE 3. Additional Evidence for Sorption of Ni-EDTA Complex by Oak Ridge Soil 
with precomplexed $\mathrm{Ni}$ (Figure 2). The $\mathrm{Ni}$ will also migrate more rapidly than if the complex were not kinetically inert, so that rapid dissociation could occur as the free EDTA concentration is reduced by complexation of soilderived elements, and the uncomplexed $\mathrm{Ni}$ could then be sorbed by the soit.

The question of sorption of a $\mathrm{Ni}$-EDTA complex was also addressed with Savannah River soil, but with less conclusive results. When precomplexed $\mathrm{Ni}$ EDTA solutions were contacted with Savannah River soil, the fraction of the Ni that was sorbed rapidly was not highly dependent on EDTA concentration (Figure 4). This behavior is similar to that observed with Oak Ridge soil and thus suggests the sorption of a Ni-EDTA complex in this soil system also. However, at EDTA concentrations below about $1 \times 10^{-4} \underline{M}$, this rapid initial sorption was followed by a continued slow sorption so that the pseudo-equilibrium position that was evidenced with Oak Ridge soil was not maintained.

Thus sorption of a Ni-EDTA complex by Savannah River soil apparently does occur. However, the pseudo-equilibrium position is not very stable, and adjustment towards the true equilibrium position occurs over a period of several months. The pseudo-equilibrium positions initially attained in this system give $\mathrm{Ni}$ Kd values approximately 30 to $50 \%$ higher than those measured with ORNL soil (Figure 2).

The behavior of $\mathrm{Ni}$ in presorbed experiments with Savannah River soil also differed from Oak Ridge soil experiments. In the Oak Ridge soil system, very little $\mathrm{Ni}$ was leached from the soil by $3.5 \times 10^{-6}$ M EDTA when the Ni had been sorbed in the absence of complexant, and there was a large difference between the fractions in solution in precomplexed and presorbed experiments (Figure 1). With Savannah River soil, however, a significant portion of the $\mathrm{Ni}$ was leached quite rapidly, and there were only moderate differences between the fractions in solution in precomplexed and presorbed experiments (Figure 5). The pattern observed in the presorption experiment, an initial increase in $\mathrm{Ni}$ concentration followed by a decrease, had been observed earlier (Swanson 1982) in the Co/EDTA/Savannah River soil system.

The reason for the enhanced stability of the sorbed Ni-EDTA complex in the Oak Ridge soil system relative to the Sayannah River soil system is not known. The difference in stability could be due to differences in solution properties or in the soil geochemistry. No data are available in the latter 


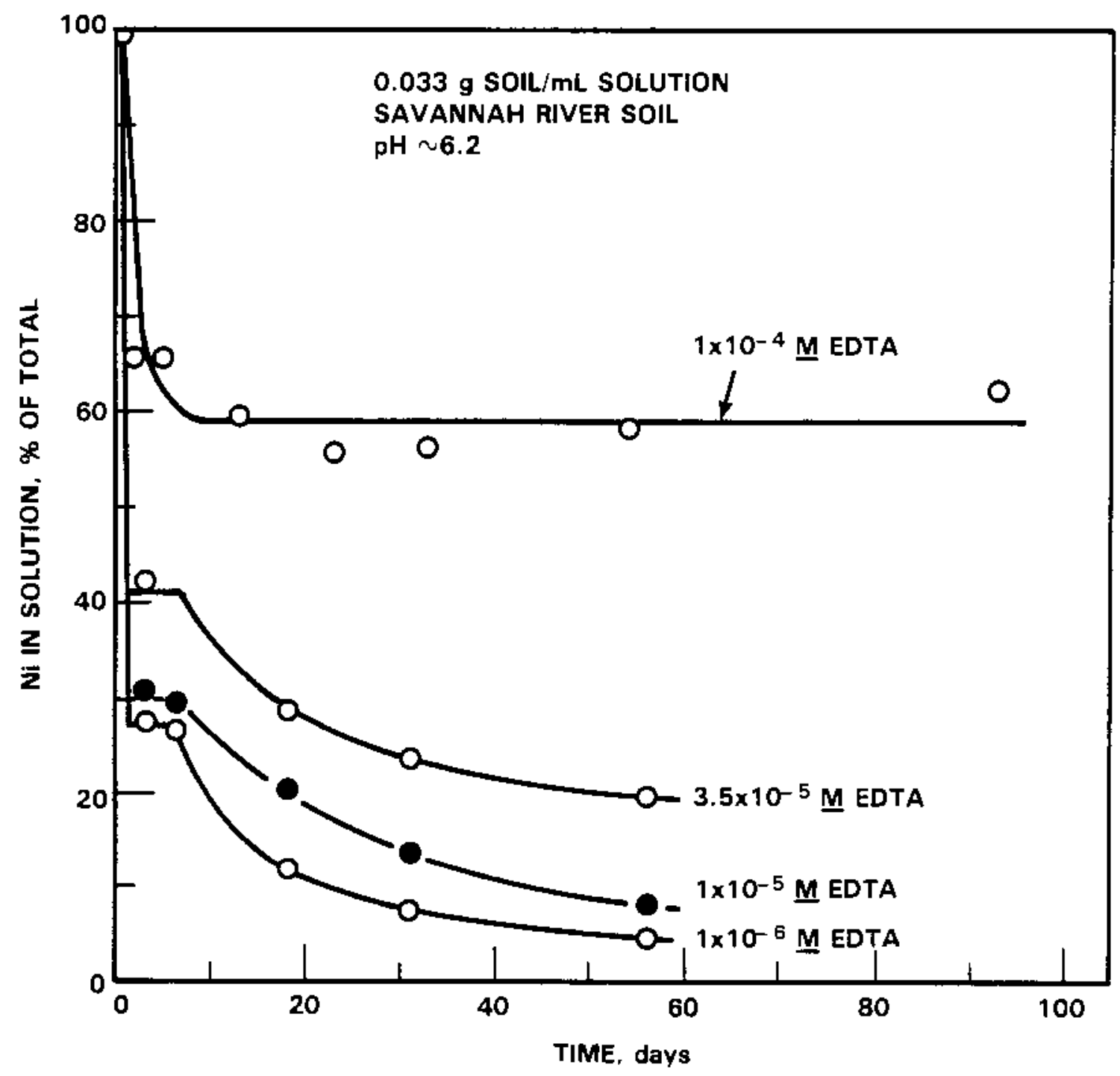

FIGURE 4. Results of Precomplexed Ni-EDTA Experiments with Savannah River Soil 


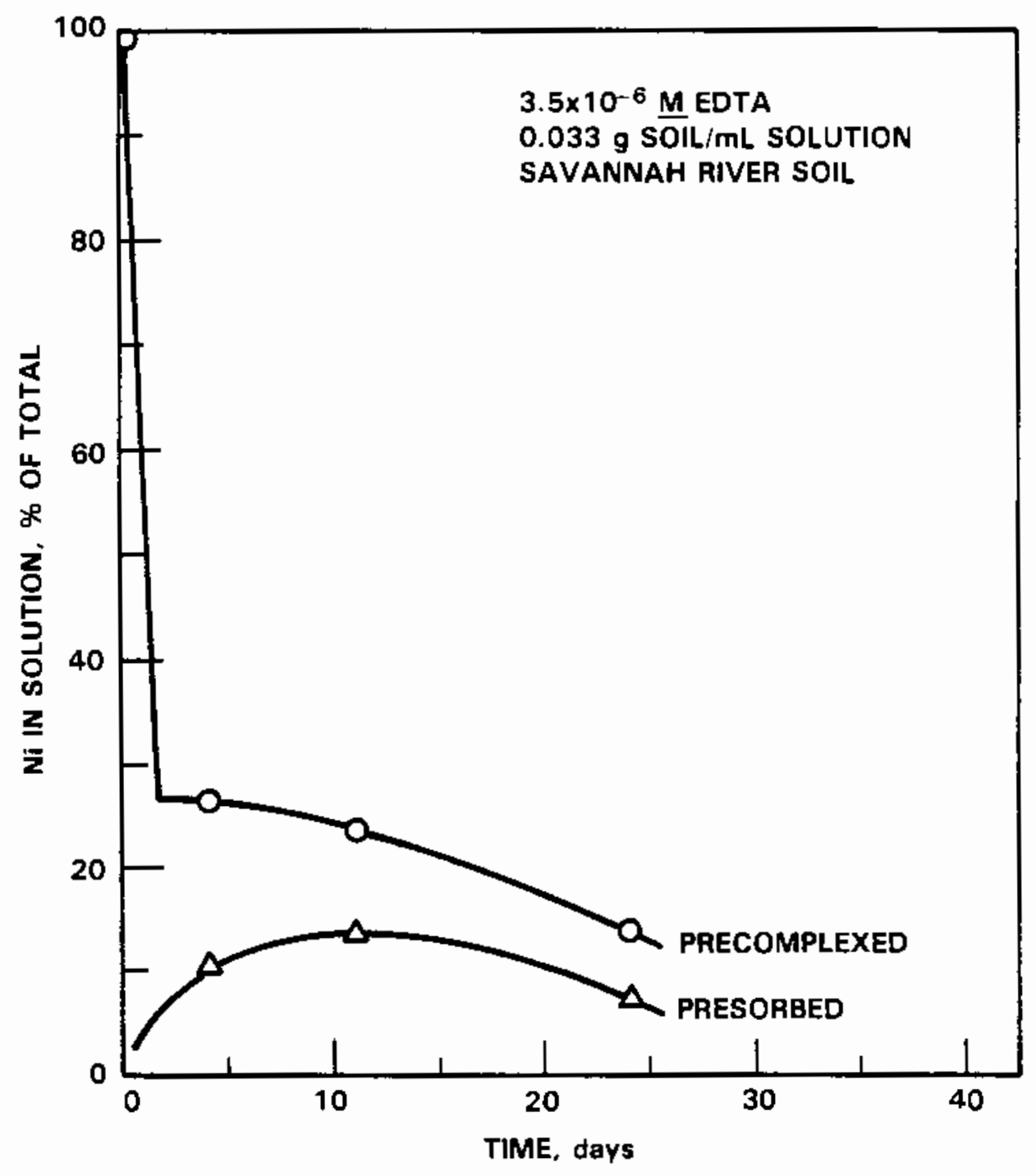

FIGURE 5. Comparison of Precomplexed and Presorbed Experiments from the Ni/EDTA/Savannah River Soil System 
area with the specific soils used here. Comparison of measured properties of solutions contacting the two soils failed to provide any obvious clue.

The solution $\mathrm{pH}$ values are comparable $(\sim 5.5)$ with the Oak Ridge and the Savannah River soils, and the concentrations of major soil-derived elements are similar, as will be shown later. Differences were found in the trace element content of the soil leachates, but it is not clear that these differences would explain the differing stabilities of the sorbed complexes in the two soil systems. Cobalt was found in EDTA leachates of Oak Ridge soil, but not of Savannah River soil. EDTA leachates of Savannah River soil contained several times more $\mathrm{Cu}$ and Mn than did leachates of Oak Ridge soil; these elements were present at about $1 \times 10^{-6} \mathrm{M}$ in a $5 \times 10^{-5} \mathrm{M}$ EDTA leachate. Basolo and Pearson (1967) discussed a rapid exchange reaction of Cu with $\mathrm{Ni}$ EDTA, which would appear to explain the observed differences in apparent stability of the pseudo-equilibrium positions in the two soil systems. However, these authors also point out that the rate of exchange of $\mathrm{Fe}$ with $\mathrm{Ni}$ EDTA is even more rapid. Since much $F e$ is present in leachates of both of these soils, it does not appear reasonable to attribute the observed differences in apparent stability of the pseudo-equilibrium positions in the Savannah River and Oak Ridge soil systems to the difference in $\mathrm{Cu}$ content of the leachates.

The rapid exchange of $\mathrm{Fe}$ with $\mathrm{Ni}$-EDTA may, however, provide at least a partial explanation for the more rapid dissociation of the Ni-EDTA complex in Savannah River soil systems than in Hanford soil systems.

\section{Co-EDTA Complex Sorption}

The conclusion that sorption of a complexed species itself was occurring with Dak Ridge soil was first reached while studying the Co/EDTA/Oak Ridge soil system. Because of the added uncertainty of an oxidation state change in the cobalt case [EDTA-complexed cobalt in air-saturated solutions is likely to be Co(III) while the cobalt will be Co(II) in the absence of complexant], the subsequent work emphasized $\mathrm{Ni}$, which is present as $\mathrm{Ni}$ (II) whether complexed or not. However, the early data with Co are pertinent and are presented here.

When a solution containing $3.5 \times 10^{-6} \mathrm{M}$ EDTA and $4 \times 10^{-8} \mathrm{M}$ Co was contacted with 0ak Ridge soil, the concentration of Co in solution rapidly decreased to 
a value which remained essentially constant over a 40 day time period (the open circle data of Figure 6 ). When most of the solution was removed and contacted with a second portion of soil, essentially the same distribution of Co was rapidly attained (the filled circle data of figure 6). Addition of fresh EDTA solution to the soil and residual solution from the first contact also rapidly gave essentially the same distribution of Co (the filled triangle data). These results show that an apparent equilibrium condition was rapidly attained in these three tests. However, since other tests showed that a much higher distribution of Co was attained (in these time periods) when soil which had sorbed uncomplexed Co was contacted with EDTA solution, it was obvious that the apparent equilibrium condition observed in the precomplexed experiments (Figure 6) must be only a pseudo-equilibrium condition that involved sorption of a Co-EDTA complex.

The results of all the tests in the Co/EDTA/ORNL soil systern are summarized in Table 3. These data show the same features as those discussed eartier for the Ni/EDTA/Oak Ridge soil system:

- poor agreement between precomplexed and presorbed (uncomplexed) experiments at low EDTA concentrations (Tubes 629 and 632)

- good agreement in second contact experiments (Tubes 603 and 618)

- good agreement between precomplexed and presorbed (complexed) experiments (Tube 618)

- small change in $\mathrm{Kd}$ values with large change in EDTA concentration in the precompiexed experiments.

Other important points from these data are:

- The Kd value for the pseudo-equilibrium positions attained during these time periods in the precomplexed experiments is independent of co concentration and soil-to-solution ratio.

- The Kd values for the pseudo-equilibrium positions in the Co/EDTA/ORNL soil systen are approximately one-fifth those measured in the Ni/EDTA/Oak Ridge soil system (Figure 2).

- At the higher EDTA concentration $\left(1 \times 10^{-4} \mathrm{M}\right)$, the agreement between precomplexed and presorbed (uncomplexed) experiments is fairly good, suggesting that a true equilibrium position is more easily achieved at nigher EDTA concentrations. 


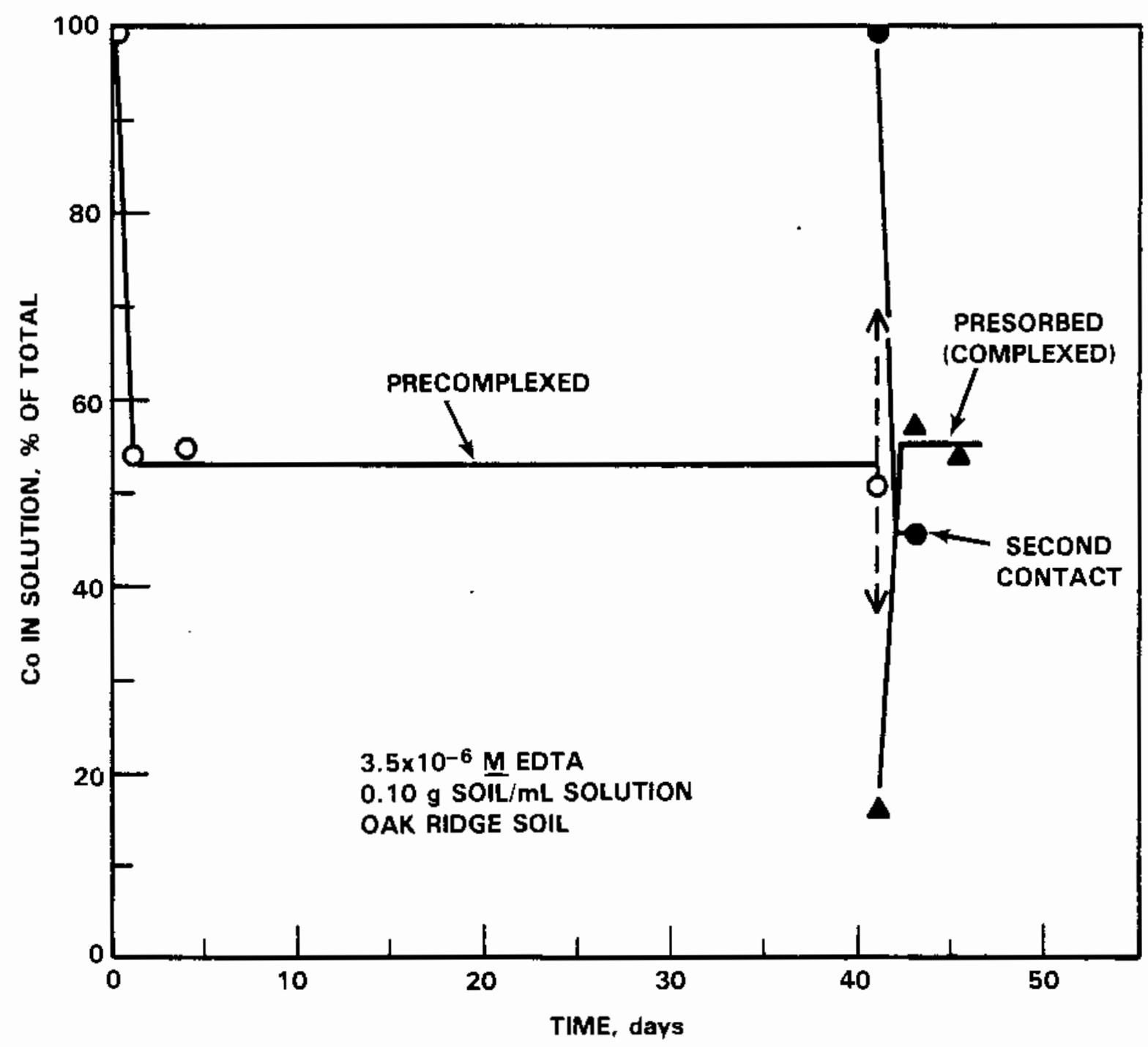

FIGURE 6. Evidence for Sorption of Co-EDTA Complex by Oak Ridge Soit 
TABLE 3. Summary of Test Results for the Co/EDTA/Oak Ridge Soil System

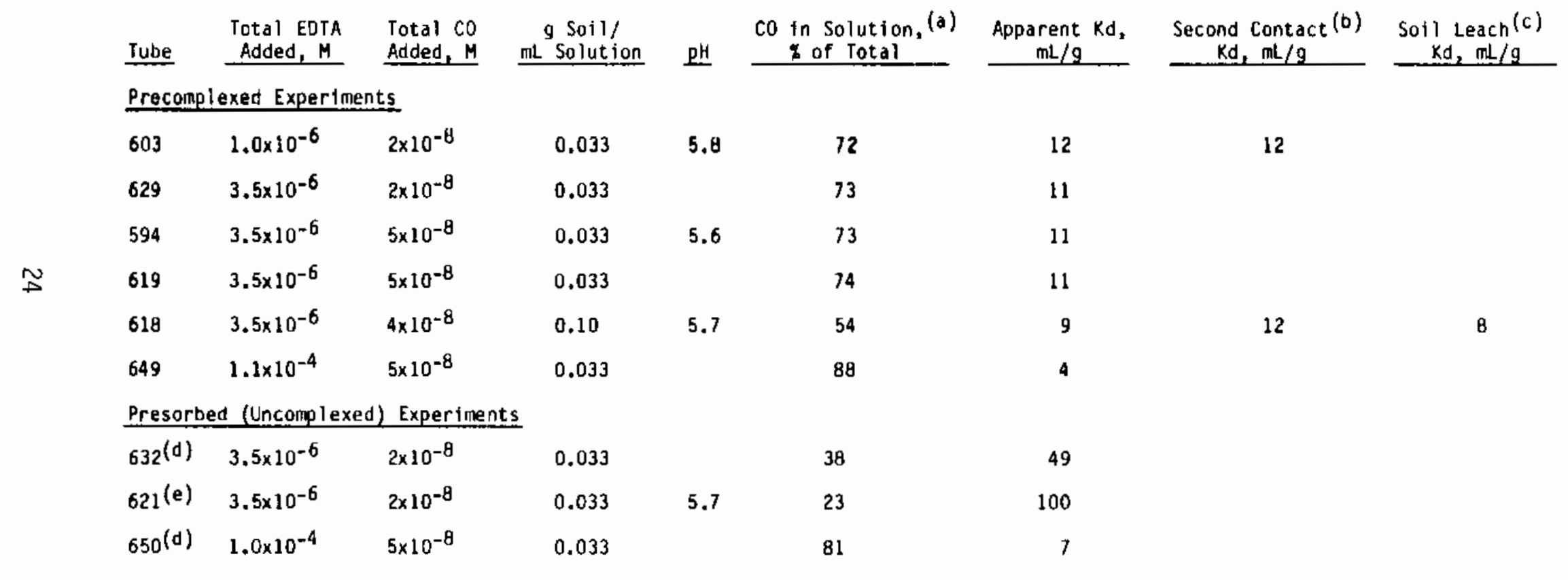

\footnotetext{
(a) After $\sim 5$ days.

(b) Solution separated from soil and contacted with a second portion of soil.

(c) Soil separated from solution and leached with a fresh portion of solution.

d) One day sorption time allowed before EDTA added.

(e) Nine day sorption time allowed before EDTA added.
} 
It is of interest to compare these data with those of Means, Crerar, and Duguid (1978) in their paper discussing the migration of a Co-EDTA compTex from an Oak Ridge burial site. They reported $\mathrm{Kd}$ values ranging from 7 to 65 $\mathrm{mL} / \mathrm{g}$ (most near 30) for the Co in soil and water from various wells in the ORNL burial grounds, at EDTA concentrations of approximately $3.4 \times 10^{-7} \mathrm{M}$. These values are higher than those measured here, but are of the same order of magnitude.

Earlier Work On Complex Sorption

Several earlier studies have been reported in which the sorption of a metal-organic ligand complex was either demonstrated or inferred. Davis and Leckie (1978) showed that the sorption of $\mathrm{Cu}$ (II) by amorphous iron (III) oxide was increased (at certain $\mathrm{pH}$ values) by glutamic acid and by 2,3-pyrazinedicarboxylic acid, and that an increase in $\mathrm{Ag}$ (I) adsorption on $\alpha$-quartz resulted from addition of ethylenediamine. These authors point out that the actual mechanism of adsorption could involve either complexation of the metals by adsorbed ligands or adsorption of the metal-ligand complex, and that these two possibilities are thermodynamically indistinguishable.

SibTey, Sanchez, and Schell (1981) found that the sorption of Co in sediment-water systems from Lake Washington and the Hudson River estuary was increased by the addition of 1,10-phenanthroline or 1-nitroso-2-naphthol, but decreased by the addition of EDTA. Means (1982) observed greater adsorption of metals by clays in the presence of oxalic acid, and identified adsorption of the oxalic acid-metal complex itself as one possible explanation.

Weiss and Columbo (1980) studied the effect of EDTA on sorption of Co and Am by commoniy encountered soil-forming minerals (shale, montmorilionite, kaolinite, illite, limonite, and vermiculite). The EDTA generally reduced sorption, but with montmorillonite the Co sorption was not affected, and the Am sorption was increased. Weiss and Columbo suggest that this behavior results from the adsorption of organic molecules by montmorillonite-type clays and comment that the presence of such clays in the soil around a disposal trench would tend to counteract the increased migration potential of organoradionuclide complexes.

Norvell and Lindsay (1982) studied the sorption of the Fe-EDTA chelate; their data allow calculation of $\mathrm{Kd} \approx 1 \mathrm{~mL} / \mathrm{g}$ for this chelate on a colorado 
soil. Lahav and Hochberg (1975) report $\mathrm{Kd}=0.57 \mathrm{~mL} / \mathrm{g}$ for the Fe-EDTA complex on a sandy soil.

In their study of the EDTA-enhanced migration of Co at 0ak Ridge, Means, Crerar, and Duguid (1976) noted that whether the Co is adsorbed as an uncomplexed ion or as an entire complex was not known, but that their experiment suggested that the uncomplexed ion was the species which was sorbed. This question was not addressed in their final pubiication (Means, Crerar, and Duguid 1978).

Except for the work of Weiss and Columbo (1980), these examples of the sorption of metal-organic ligand complexes were either too atypical of Towlevel waste disposal conditions or too indefinite in proof to emphasize the potential importance of this phenomenon, with the result that it was generally overlooked in radionuclide migration considerations.

COMPLEXANT DECOMPOSITION AND SORPTION

Tests conducted this year have confirmed earlier indications (Swanson 1982) that citrate decomposition was occurring during the course of radionuclide sorotion experiments. Results of similar studies with EDTA are also presented; decomposition was observed in both Hanford and Savannah River soil systems, and sorption was observed with Savannah River and Oak Ridge soils.

\section{Citrate Decomposition}

Previous results with citrate complexant suggested that citrate was decomposing fairly rapidly under the experimental conditions (Swanson 1982). Such decomposition has now been proved in experiments in which citrate concentration was followed by using ion chromatography (IC) or ${ }^{14} \mathrm{C}$-labeled citrate.

The results obtained with Hanford soil and two different concentrations of citrate are given in Figure 7. At an initial citrate concentration of $0.005 \mathrm{M}$, nearly a1l of the citrate had decomposed within 10 days. There was general agreement between an experiment using IC and one using ${ }^{14} \mathrm{C}$-1abeled citrate. 


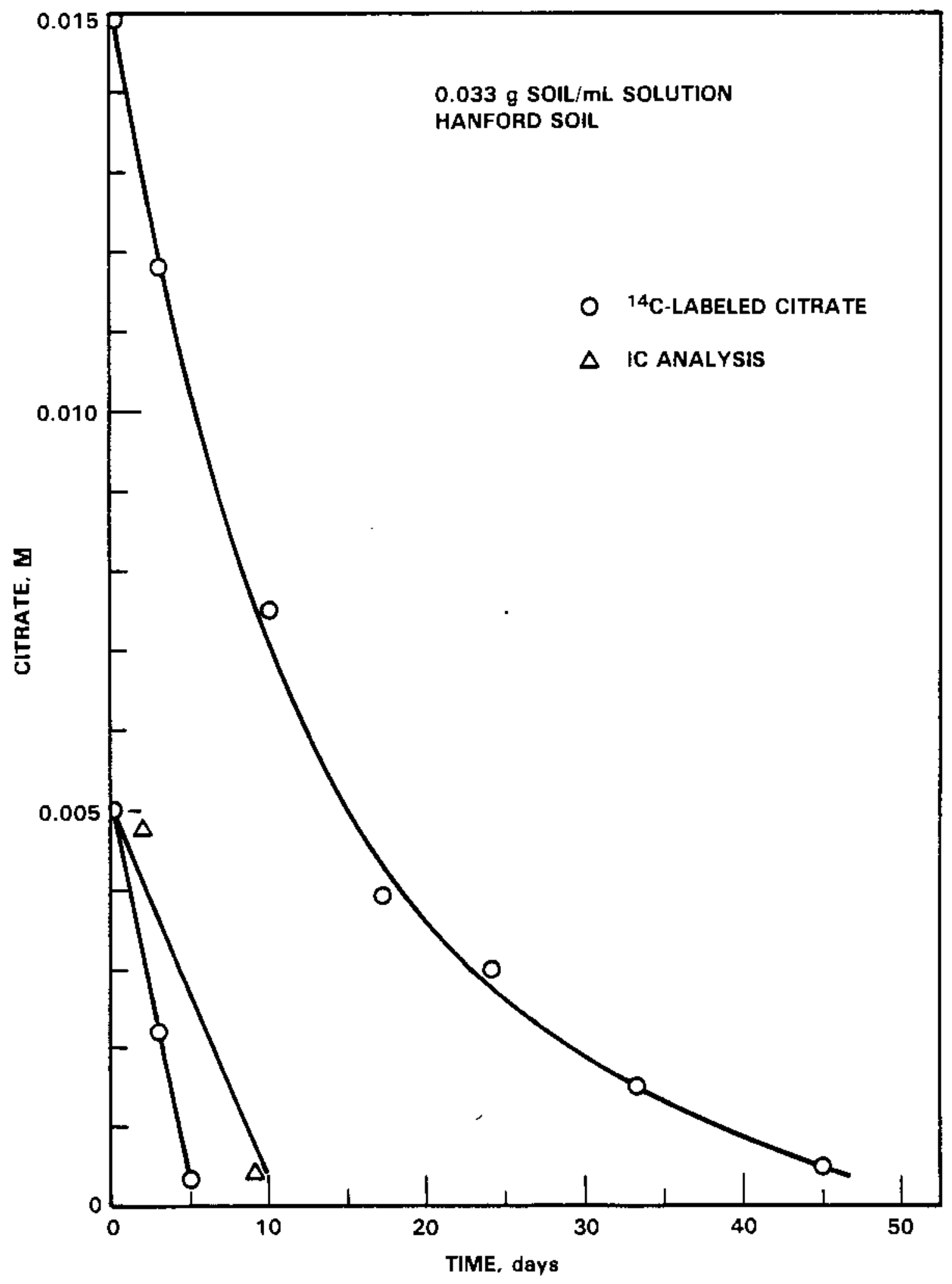

FIGURE 7. Disappearance of Citrate Under Experimental Conditions 
A similar experiment using IC was done with Savannah River soil. The resuits feil between those obtained by the two analytical methods with Hanford soil. Thus, the rate of citrate decomposition is essentially the same in the two soil/groundwater systems.

At a citrate concentration of $0.015 \mathrm{M}$, the initial rate (mole/day) of citrate decomposition was about the same as at $0.05 \mathrm{M}$ citrate. The reaction then slowed, however, and a longer time was required for complete destruction; the $0.015 \mathrm{M}$ citrate data are fit quite well by assuming a first-order reaction with a half-life of 9 days. The possibility that the decrease in ${ }^{14} \mathrm{C}$ concentration was due to sorption or precipitation of citrate, rather than to decomposition, was ruled out by the following test. The citrate concentration was increased to $0.2 \mathrm{M}$ with non-labeled citrate and the mixture shaken for 4 days. No ${ }^{14} \mathrm{C}$ reentered the solution, so it was concluded that none of the initially-added citrate remained to exchange with that added later.

This possibly complex reaction was not examined further. However, the evidence is clear that citrate decomposition is quite rapid in these soil/groundwater systems. This lends support to the thesis (Swanson 1982) that citrate-containing nuclear wastes would be much less hazardous than wastes containing more stable (and stronger) complexants such as EDTA.

\section{EDTA Decomposition and Sorption}

Experiments were also conducted to address the behavior of EDTA under the conditions used in the radionuclide sorption experiments. Figure 8 presents the results obtained with three different soils (Hanford, Savannah River, and Oak Ridge) and two different methods of analysis (gas chromatography and counting of ${ }^{14} \mathrm{C}-1$ abeled EDTA). Very poor agreement was obtained between the two analytical methods; it is more likely that the gas chromatographic values are correct because that method is specific for EDTA, whereas the ${ }^{14} \mathrm{C}$ method cannot distinguish between EDTA and partial decomposition products of EDTA which also remain in solution.

The two-fold reduction in EDTA concentration observed during a 2 month time period, plus the evidence that EDTA decomposition products (which may themselves be complexants) remain in solution, indicate that quantitative interpretation of long-term radionuclide distribution experiments will be very difficuit. However, such experiments are still important because they parallel the behavior that will be observed in the environment. 


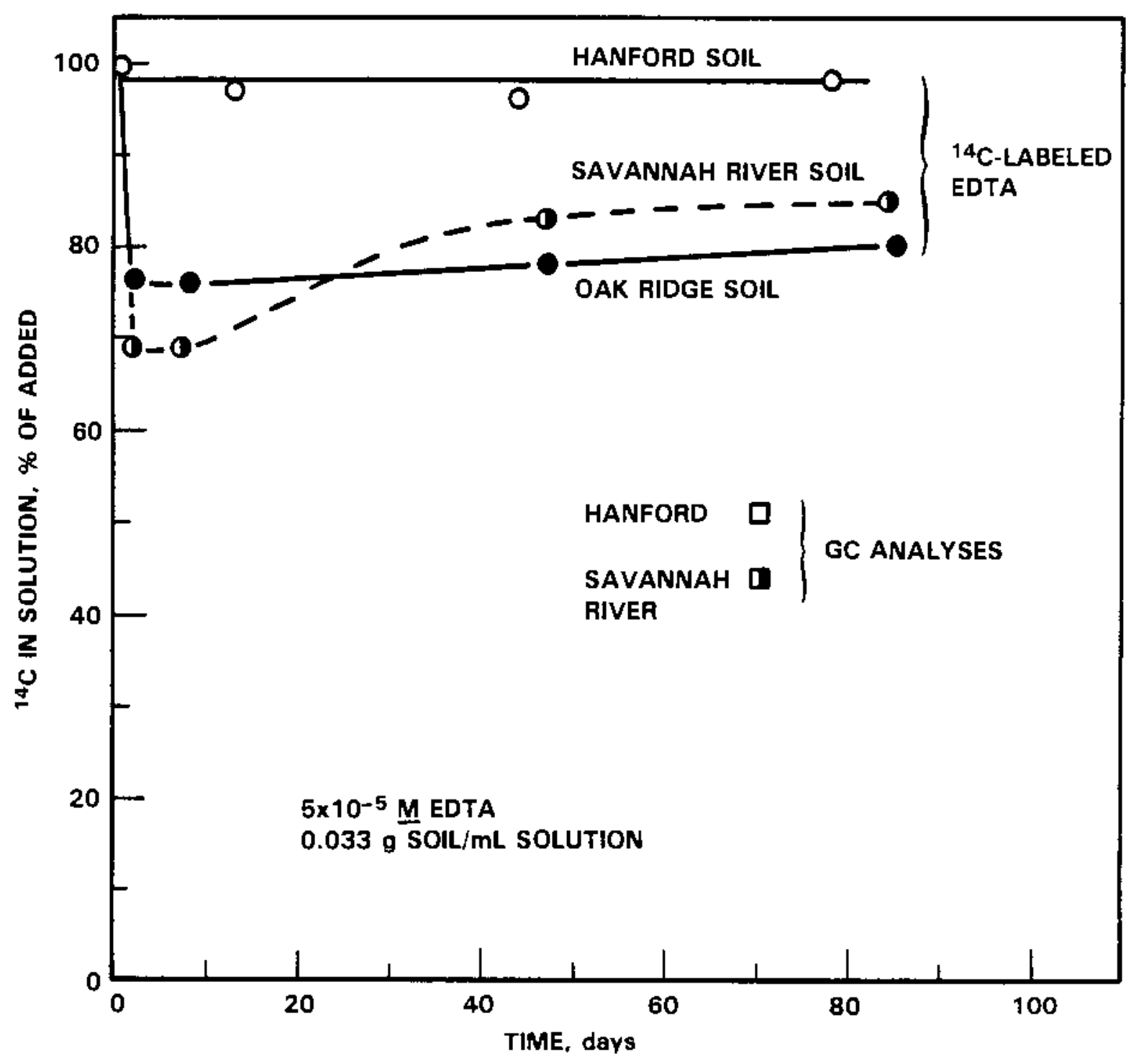

FIGURE 8. Apparent EDTA Stability Under Experimental Conditions 
Another point should be made regarding the stability of EDTA (and other complexants); that is, that insufficient data currently exist to predict accurately the degradation rates of complexants in the environment. Means and Alexander (1981) point out that a major discrepancy exists between laboratorymeasured biodegradation rates of EDTA and the persistence of EDTA in 10 to 20 year-old wastes at the Dak Ridge and Maxey Flats disposal sites. These authors comment that the true indication of a chemical's persistence in the environment comes frorn actual field data.

While the experiments with ${ }^{14} \mathrm{C}$-l abeled EDTA appear to be meaningless insofar as EDTA stability is concerned, they should be of value in studying sorption of EDTA by the soils. Sorption is a rapid reaction which should be compiete before EDTA decomposition proceeds to a significant extent. The initial rapid drop in EDTA concentration observed with Savannah River and Oak Ridge soils (Figure 8) is thus attributed to EDTA sorption. No sorption of EDTA by Hanford soil was observed.

EDTA sorption data obtained at lower concentrations are shown in Figure 9. The fraction of the EDTA that was rapidly sorbed by the 0ak Ridge soil increased slightly as the EDTA concentration decreased, being about $60 \%$ at $2 \times 10^{-7} \mathrm{M}$ EDTA and $40 \%$ at $1 \times 10^{-6} \mathrm{M}$ EDTA (these fractions give $\mathrm{Kd}$ values of about $45 \mathrm{~mL} / \mathrm{g}$ and $20 \mathrm{~mL} / \mathrm{g}$, respectively). As before (Figure 8 ), the ${ }^{14} \mathrm{C}$ content of the solution then increased gradually, presumably due to decomposition of the EDTA into species that are not sorbed by the soil.

\section{LEACHING OF ELEMENTS FROM SOILS}

The potential importance of elements leached from the soil on the effect of organic complexants on radionuclide sorption was recognized in the earlier work (Swanson 1981 and 1982), but little data was obtained. Data obtained this year on the leaching of elements from the various soils are contained in the appendix and will be discussed here.

A simplified comparison of the leaching of elements likely to be complexed from the three soils examined is contained in Table 4. EDTA in the Hanford soil system increases the concentrations of $\mathrm{Ca}$ and $\mathrm{Zn}$ in solution; surprisingly, the concentrations of these two ions increase more than the concentration of EDTA added (by a factor of 2.6). There is little or no leaching of Al or Fe from the Hanford soil. With Savannah River soil, EDTA 


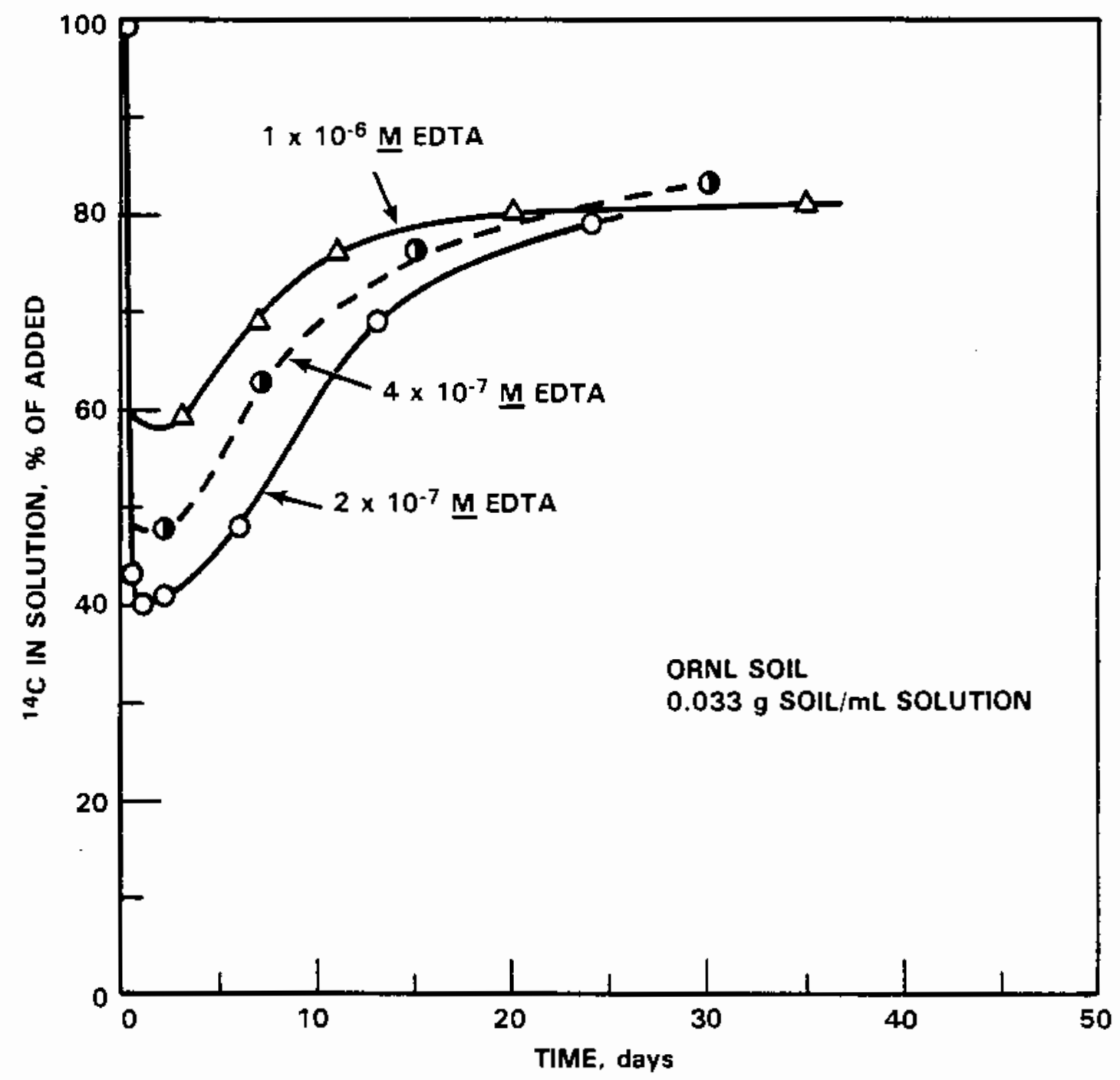

FIGURE 9. Apparent Sorption of EDTA by Oak Ridge Soil 
TABLE 4. Complex-Forming Elements Leached from Soils (a)

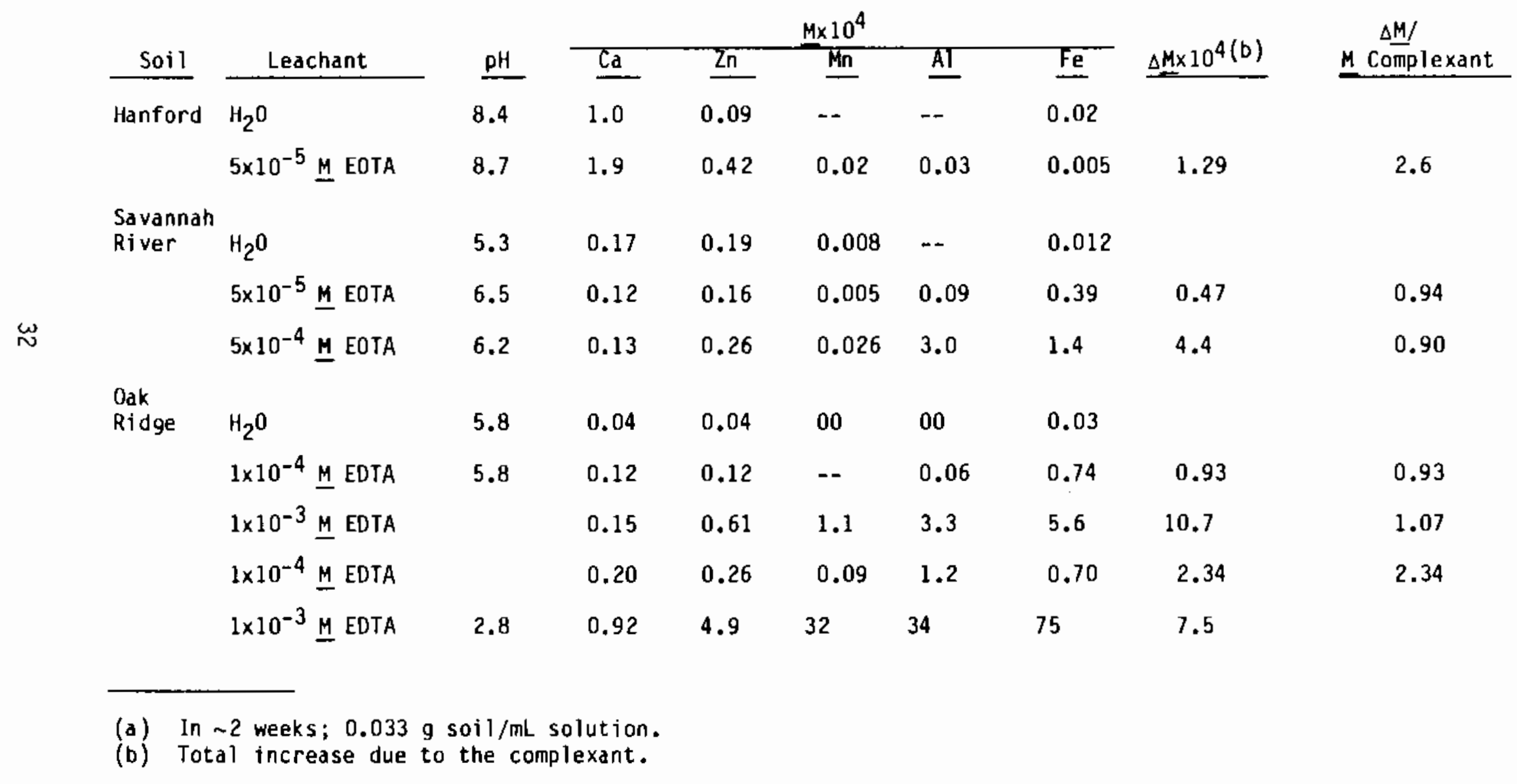


Causes large increases in the concentrations of $\mathrm{Fe}$ and $\mathrm{Al}$, and the magnitude of this increase is approximately equal to the concentration of EDTA added. Large increases in $\mathrm{Fe}$ and $\mathrm{Al}$ concentrations also result from the presence of EDTA in the solution contacting Oak Ridge soil, and $M n$ and $2 n$ are also significantly affected.

With EDTA and both the 0ak Ridge and Savannah River soils, the sum of the concentration increases of these elements was essentially equal to the concentration of EDTA added. This result is probably somewhat coincidental, as will be discussed later, especially since sorption of appreciable fractions of EDTA was observed earlier. However, with NTA the sum of the concentration increases was greater than the concentration of NTA added, especially at the higher NTA concentration.

With concentrations of complexing metal ions equal to or greater than the concentrations of ligand, as observed here, the concentration of free ligand (which is what is important to radionuclide-ligand equilibria) is very low. Norvell (1972) calculated that a $1 \times 10^{-4}$ M EDTA solution in equilibrium with $\mathrm{H}^{+}, \mathrm{Ca}^{2+}, \mathrm{Mg}^{2+}, \mathrm{Al}^{3+}$, and $\mathrm{Fe}^{3+}$ at a $\mathrm{pH}$ of 6 would contain only about $1 \times 10^{-11} \underline{\mathrm{M}}$ free EDTA. This is still sufficient to complex Ni quite strongly; the ratio of complexed $\mathrm{Ni}$ to uncomplexed $\mathrm{Ni}$ would be about $1 \times 10^{4}: 1$ in such a solution (Norvell 1972).

The data of Table 4 are intended to provide a gross qualitative comparison of the leaching of elements from the three soils; more detailed examination of the data presented in the appendix is also instructive. Figure 10 contains data obtained with Savannah River soil at two EDTA concentrations; the soil-derived elements $\mathrm{Fe}, \mathrm{Al}$, and $\mathrm{Zn}$ are plotted (as a ratio of their concentration to the added EDTA concentration). Aluminum increases rapidiy at first, much more rapidly than $\mathrm{Fe}$, but $\mathrm{Al}$ later decreases as Fe increases. The replacement of $A 1$ in solution by $F e$ is predictable from the magnitude of the EDTA complex stability constants (and the limited solubility of uncomplexed A1); as seen in Table 5, the Fe(III)-EDTA stability constant is about $1 \times 10^{9}$ times greater than that for Al-EDTA, and the solubility of uncomplexed AT is only about $1 \times 10^{-12} \mathrm{M}$ at $\mathrm{pH} 7$. The initial rapid increase in $\mathrm{Al}$ concentration is presumably because more $A 1$ than $F e$ is present in the soil in a rapidly leachable form. The stability constant for the $Z n$-EDTA complex is approximately the same as that for the Al complex, so the $\mathrm{Zn}$-EDTA complex must 
TABLE 5. Properties of Soil-Derived Metal Ions

\begin{tabular}{|c|c|c|c|}
\hline Metal Ion & $\begin{array}{l}\text { EDTA Complex } \\
\text { Formation } \\
\text { Constant a) }\end{array}$ & $\begin{array}{l}\text { NTA Complex } \\
\text { Formation } \\
\text { Constant }(\mathrm{a})\end{array}$ & $\begin{array}{l}\text { Solubility Product } \\
\text { of Amorphqus } \\
\text { Hydroxide }\end{array}$ \\
\hline $\mathrm{Ca}^{2+}$ & $3.2 \times 10^{11}$ & $6.3 \times 10^{7}$ & $5.5 \times 10^{-6}$ \\
\hline $\mathrm{Mn}^{2+}$ & $3.2 \times 10^{14}$ & $1.3 \times 10^{8}$ & $1.9 \times 10^{-13}$ \\
\hline $\mathrm{Zn}^{2+}$ & $1.6 \times 10^{17}$ & $1.6 \times 10^{11}$ & $1.2 \times 10^{-17}$ \\
\hline $\mathrm{Al}^{3+}$ & $4.0 \times 10^{17}$ & $4.0 \times 10^{11}$ & $1.3 \times 10^{-33}$ \\
\hline $\mathrm{Fe}^{3+}$ & $3.2 \times 10^{26}$ & $1.0 \times 10^{17}$ & $4 \times 10^{-38}$ \\
\hline
\end{tabular}

(a) Norve11 (1972).

(b) Dean (1973).

also dissociate (along with the Al complex) as the Fe content increases. However, the $\mathrm{Zn}$ can remain in solution because the solubility of uncomplexed $\mathrm{Zn}$ is relatively high at $\mathrm{pH}$ values like these (about $1 \times 10^{-3}$ M at $\mathrm{pH} 7$ and $1 \times 10^{-1} \mathrm{M}$ at $\left.\mathrm{pH} 6\right)$.

In the experiment at $5 \times 10^{-5} M$ EDTA (Figure 10a), the sum of the concentrations of $\mathrm{Fe}, \mathrm{Al}$, and $\mathrm{Zn}$ exceeded the concentration of EDTA added at all time intervals. Because of the strength of the complexes formed by these elements with EDTA, the concentration of uncomplexed EDTA was only a small fraction of the added EDTA throughout this experiment. At the higher EDTA concentration (Figure 10b), this condition was not reached for about 2 weeks (at this soil-to-solution ratio). This variation in time taken to reach complexant saturation should be kept in mind when comparing results of radionuclide distribution experiments with Savannah River soil at different complexant concentrations; the free complexant concentrations may differ much more than the total complexant concentrations because of the limited leach rates of the soil-derived elements.

Similar results are presented in Figure 11 for Oak Ridge soil and EDTA solutions of different concentrations. The Fe concentration increases more rapidly here than with Savannah River soil (Figure 10) so that there is less opportunity to see the growth and decline of the Al concentration. This is observed at the high EDTA concentration, however, where more time is required 

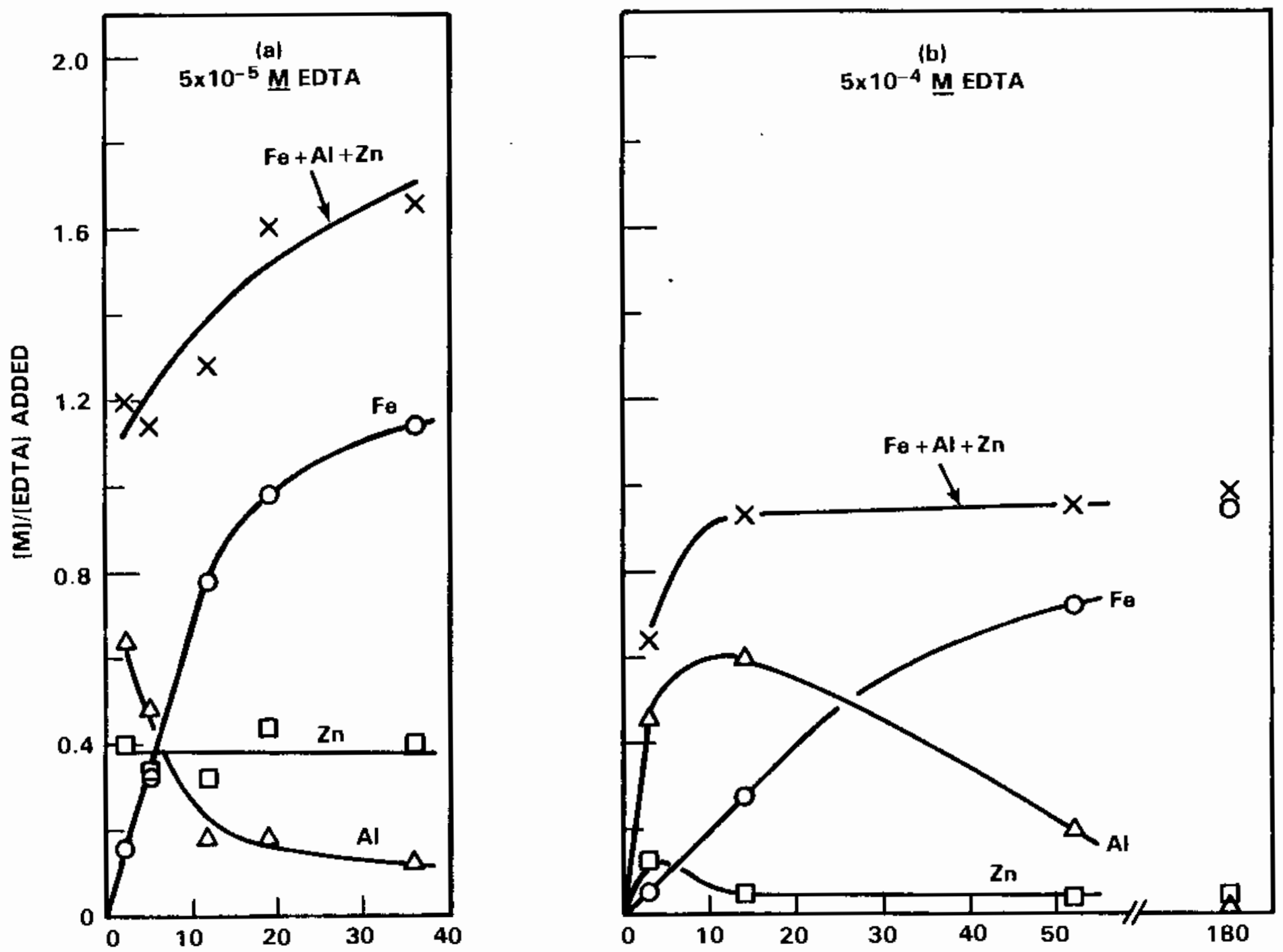

TIME, days

FIGURE 10. Major Complex-Forming Elements Leached from Savannah River Soi1 at Two Different EDTA Concentrations 

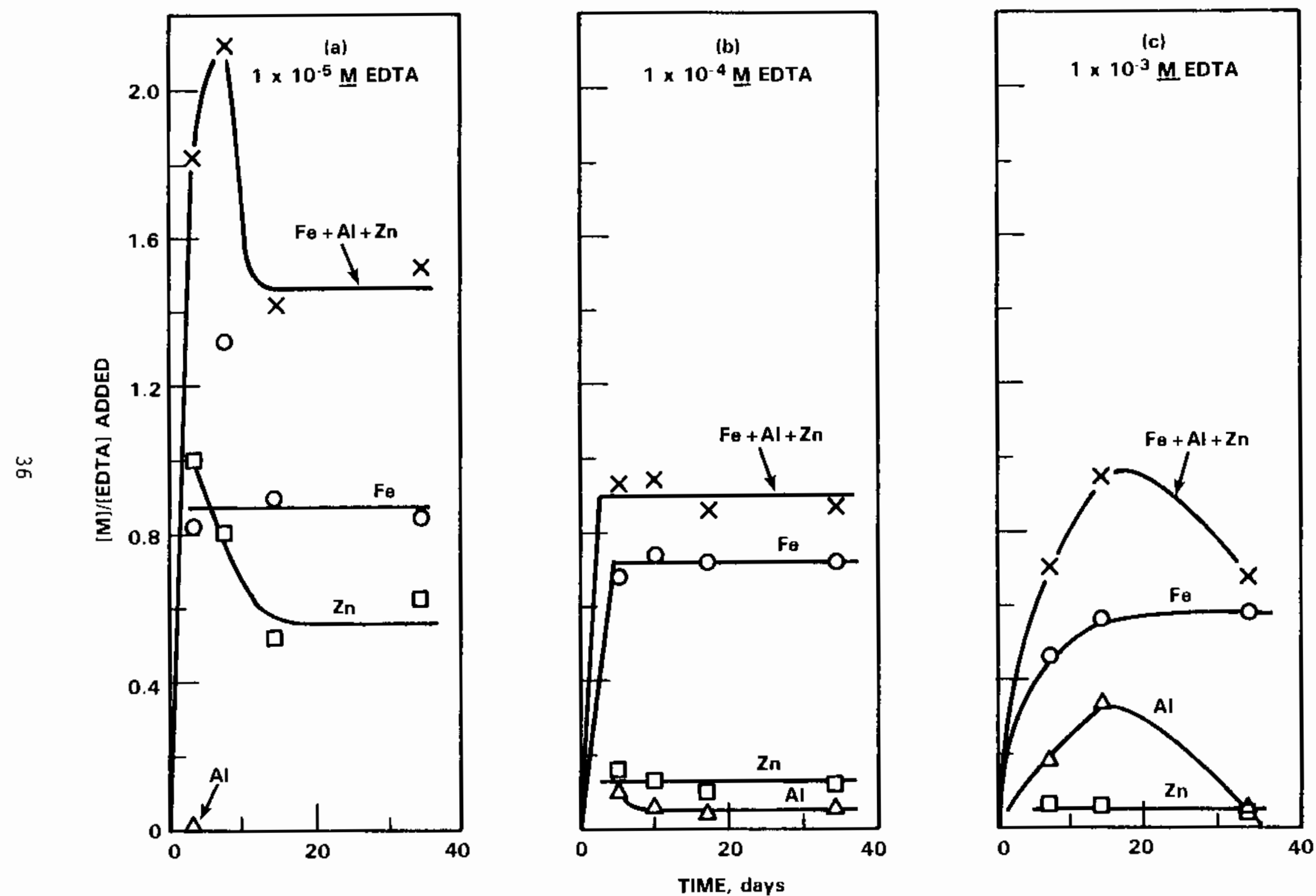

FIGURE 11. Major Complex-Forming Elements Leached from Oak Ridge Soil at Three Different EDTA Concentrations 
for the Fe to reach its maximum value. As with Savannah River soil, the time required to leach enough complex-forming metal ions from Oak Ridge soil to equal the EDTA concentration increased with increasing EDTA concentration, so that the free EDTA concentration varied more with time at the high concentration than at the low concentration. The reasons for the apparently erratic $\mathrm{Zn}$ and Fe data at $1 \times 10^{-5} \mathrm{M}$ EDTA (Figure 1la) are not understood.

It can be argued that perhaps radionuclide distribution measurements as a function of time, as reported earlier (Swanson 1981 and 1982) and elsewhere in this report, would be nore meaningful if the radionuclides were not introduced to the system until after the soil-derived element/complexant reactions have reached equilibrium. Such experiments would more closely simulate the possible cases where the groundwater contains complexants (perhaps from some nonradioactive waste disposal site or industrial activity) before it enters the LLW disposal site, and where the groundwater picks up complexants from one location in the LLW disposal site before it encounters radionuclides in another location. However, such experiments would not simulate the condition most likely to occur in a waste disposal site, which is the simultaneous exposure of complexant and radionuclide to the soil, as well as the experiments that have been done.

The Oak Ridge and Savannah River soils were also leached with EDTA solutions at a soil-to-solution ratio of $0.001 \mathrm{~g} / \mathrm{mL}$ (33 times lower than normally used) to see how much of the various metal ions would leach from the soil when an excess of complexant is present. The results are presented in Table 6. The 0ak Ridge soil contains much greater amounts of readily leachable, EDTA-complexable elements than does the Savannah River soil; only in the case of $Z n$ are the quantities equivalent in the two soils.

Other observations from the data of the appendix are:

- Different results were obtained from two batches of Savannah River soil leached with $5 \times 10^{-5} \mathrm{M}$ EDTA. The rate of leaching of Fe was greater with Batch 1 than with Batch 2, and more Al was found initially with Batch 2 than with Batch 1. These factors are probably related, as discussed earlier. 
TABLE 6. Readily Leachable Quantities of
Complex-Forming Elements

\begin{tabular}{|c|c|c|c|c|}
\hline & $\frac{\text { Dak Ridg }}{14 \text { Days }}$ & $\begin{array}{l}\text { Soil (b) } \\
34 \text { Days } \\
\end{array}$ & $\begin{array}{l}\text { Savannah } \\
14 \text { Days } \\
\end{array}$ & $\frac{\text { River Soil }}{34 \text { Days }}$ \\
\hline $\mathrm{Ca}$ & 1.4 & 2.0 & 1.0 & 0.7 \\
\hline $\mathrm{Zn}$ & 6.5 & 3.8 & 4.0 & 4.4 \\
\hline$M n$ & 3.9 & 3.9 & 0.04 & 0.03 \\
\hline $\mathrm{A} 1$ & 3.0 & 3.2 & 0.7 & 0.8 \\
\hline $\mathrm{Fe}$ & 7.8 & 9.0 & 0.7 & 0.5 \\
\hline
\end{tabular}

(a) Quantities are (g element/g soil) $\times 10^{3}$.

(b) $0.001 \mathrm{~g} \mathrm{soil/mL}$ solution; $1 \times 10^{-3} \mathrm{M}$ EDTA. EDTA molarity/sum of element molarities $=2$.

(c) $0.001 \mathrm{~g} \mathrm{soil} / \mathrm{mL}$ solution; $5 \times 10^{-4} \mathrm{M}$ EDTA. EDTA molarity/sum of element molarities $=4$.

- More rapid leaching of Fe from Savannah River soil by $5 \times 10^{-5} \mathrm{M}$ EDTA occurred at a soil-to-solution ratio of $0.10 \mathrm{~g} / \mathrm{mL}$ than at a ratio of $0.033 \mathrm{~g} / \mathrm{mL}$. This is expected because of the increased surface area.

- More rapid leaching of Fe from both Savannah River and Oak Ridge soils resulted when they were contacted with water for 15 days before EDTA was added.

Although their values are not included in the appendix, some of the soil leach solutions contained $\mathrm{Ni}$ and $\mathrm{Co}$. The concentrations of these elements are of particular interest because they could affect the behavior of $\mathrm{Ni}$ and $\mathrm{Co}$ radionuclides. There appear to be significant amounts of $N i$ and $\mathrm{Co}$ in the Oak Ridge soil, but little or none was found (detection 1 imit $\sim 5 \times 10^{-7} \mathrm{M}$ in our experiments) in leachates of Savannah River or Hanford soils. The leaching of Co from 0ak Ridge soil by EDTA proceeded gradualiy with time, and was faster and more extensive at higher EDTA concentrations (Figure 12). With NTA, the leaching of Co was initially more rapid and extensive than with EDTA, but a decreasing Co concentration was then observed. This observed decrease may have been the result of the greater tendency of NTA to decomose (Means and Alexander 1981). No $\mathrm{Ni}$ was found in the EDTA leachates, but the $\mathrm{Ni}$ concentrations found in the NTA leachate were generally about one-haif the Co concentrations. 


$$
E
$$


These concentrations of soil-derived $\mathrm{Ni}$ and $\mathrm{Co}$ are much higher than the concentrations normally added with the radionuclide solution $\left(\sim 5 \times 10^{-9} \underline{M} \mathrm{Ni}\right.$ and $\left.\sim 5 \times 10^{-8} M \mathrm{Co}\right)$. Whether rapid exchange occurs between the atoms from the two sources is not known.

\section{COMPLEXANT EFFECTS}

Earlier results have shown the importance of kinetically inert complexes to radionuclide migration. When the rate of complex dissociation is very slow and the complex itself is not sorbed by the soil, the mobility of precomplexed radionuclides will be much greater than that predicted from equilibrium considerations. In the extreme case, kinetically inert complexes could migrate at the same speed as the groundwater. Rapid dissociation of the complexes, so that the uncomplexed radionuclide can be sorbed by the soil, is desirable. We have previously reported large differences in the rates of complex dissociation with various complexant solutions and with various soils. We have now obtained data with two additional complexants and with more complicated, commercially available decontamination solutions. Commercial Decontamination Solutions

One of the major uses of organic complexants in the nuclear industry is in the decontamination of nuciear power plants. The wastes from these activities thus provide a major source of complexants in low-level waste disposal sites, unless they are treated before disposal.

The three commercial decontamination solutions tested here had been used in decontamination tests on the Surry nuclear power plant's failed steam generator, which is undergoing examination at PNL. The compositions of the three solutions tested are proprietary, but their primary ingredients are known to include organic complexants.

Different results were obtained with each of the three solutions, again illustrating the fact that all organic complexants should not be considered to be equaliy poor with regard to radionuclide migration. With Hanford soil and tenfold dilutions of the solutions (Figure 13), little or no decrease in contained ${ }^{60}$ Co activity was observed over a 40 day contact time with solution $A$, while $<10 \%$ of the co remained in solution after only 6 days with solution $C$. 


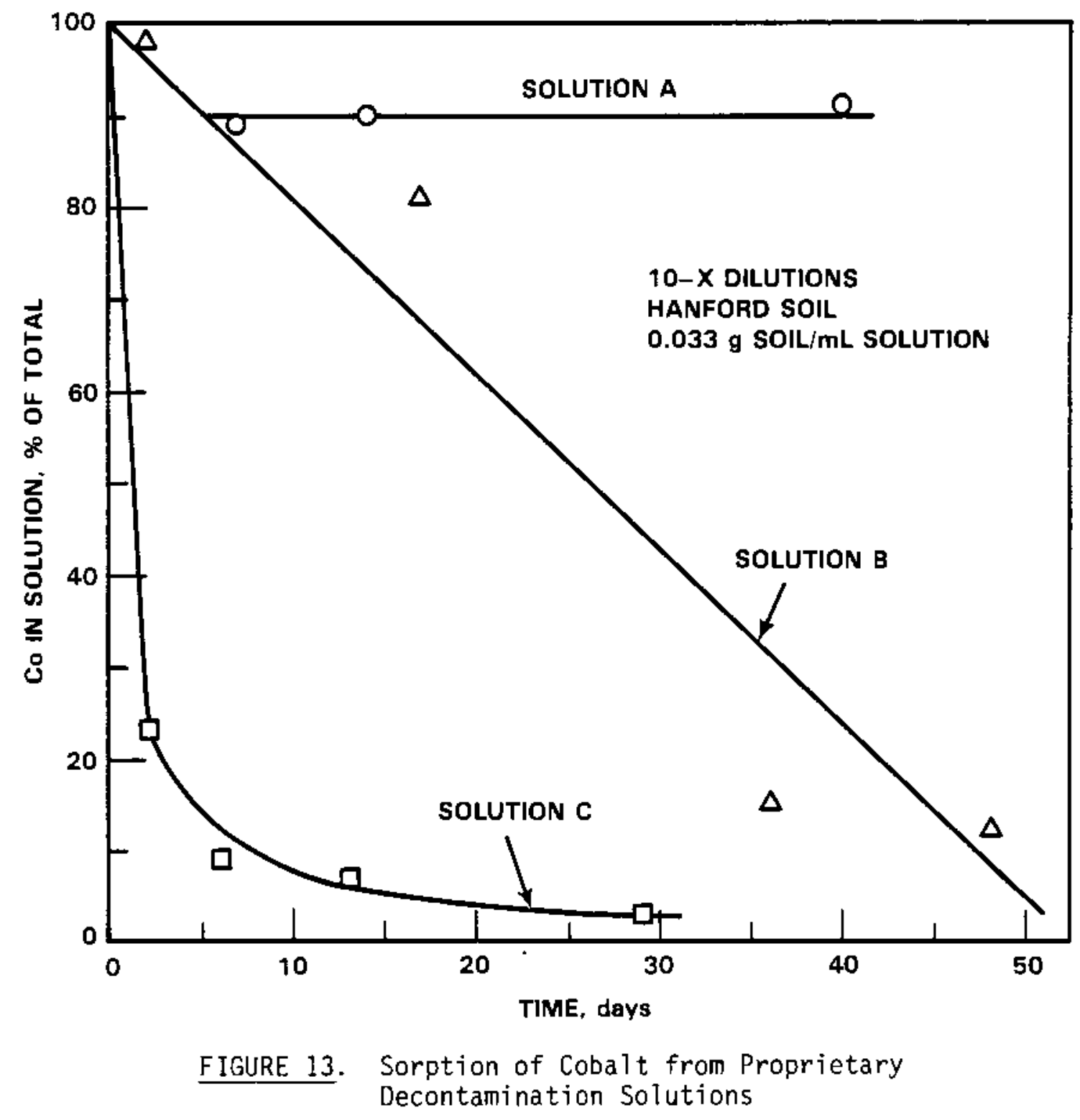


Solution B showed intermediate behavior; the Co concentration gradually decreased until only $10 \%$ remained after 50 days.

Solution A was also tested with soil from the Savannah River site. The complex dissociated more rapidly in the Savannah River soil case; $<10 \%$ of the Co was still in solution after about 20 days. This behavior is comparable to that observed earlier in tests with simple complexant solutions.

It should be mentioned that there are plans to process decontamination solutions by ion exchange before they are disposed of, to separate the contained radionuclides from the complexants. If this is done, then solutions like those tested here would not be wastes, and the Co behavior observed here could be atypical. The behavior of the radionuclides sorbed from complexant solutions onto ion exchange resins would probably be different; this is an area that could profit from additional study.

Additional Complexants

Large differences between the rates of dissociation of $\mathrm{Ni}$ and $\mathrm{Co}$ complexes of EDTA, DTPA, oxalate, and citrate in Hanford soil systems were revealed in previous work (Swanson 1982). The strong complexants, EDTA and DTPA, formed complexes that dissociated more slowly than the weaker complexants, oxalate and citrate. It is well known that there is no necessary relationship between the thermodynamic strength of a reaction and the rate at which the reaction occurs, so additional complexants were examined in an effort to find strong complexants whose $\mathrm{Ni}$ and Co complexes dissociate rapidly. Rapid complex dissociation is desirable from a waste disposal standpoint, while complexant strength may be desirable in decontamination operations.

The additional complexants examined were HEDTA and NTA, which are intermediate to those previously examined in the stability of the complexes they form with $\mathrm{Ni}$, as shown by the data presented by Norvell (1972):

\begin{tabular}{lc} 
Complex & Log of \\
\cline { 2 - 2 } Ni -DTPA & 21.3 \\
Ni -EDTA & 19.5 \\
Ni -HEDTA & 17.7 \\
Ni -NTA & 12.2 \\
Ni -Citrate & 6.1 \\
Ni -Oxalate & 4.9
\end{tabular}


The Hanford soil system was used in the experiments because that is where slow dissociation reactions are more likely to be observed, and $\mathrm{Ni}$ was the radionuclide used for the same reason. Very slow equilibration was observed with HEDTA; in experiments with $2 \times 10^{-6}$ M HEDTA, $>90 \%$ of the Ni remained in solution after 2 months of soil contact when the $\mathrm{Ni}$ was complexed before it was exposed to the soil, and $<5 \%$ of the $\mathrm{Ni}$ entered the solution in 2 months when the $\mathrm{Ni}$ was sorbed by the soil before the HEDTA was added. Much faster equilibration was observed with NTA.

The results with NTA are summarized in Figure 14. Close agreement was obtained between precomplexed (circle data) and presorbed (triangle data) experiments within about 1 month, indicating that an apparent equilibrium position was attained within that time. The data at $2 \times 10^{-6} \underline{M}$ and $6 \times 10^{-6} \underline{M}$ NTA gave apparent $K d$ values that decrease approximately in proportion to increases in the added NTA concentration. However, a much larger effect was observed on increasing the NTA concentration to $2 \times 10^{-5}$ M, for reasons which are not known.

Because of its more rapid equilibration with $\mathrm{Ni}$ (and presumably also $\mathrm{Co}$ ), it appears that wastes containing NTA would be less of a problem in a waste disposal site than wastes containing DTPA, EDTA, or HEDTA. Another factor that supports this conclusion is that NTA is more highly biodegradable (Means and Alexander 1981) and thus would have a shorter lifetime in the environment.

OTHER RESULTS

Partial data were obtained in several different areas of investigation. These data are less detailed and definitive, but they do add additional bits and pieces of information of potential importance and are presented for completeness.

Difference in Soil Batches

In addition to the differences in radionuclide behavior among soils from the different sites, differences were also observed between different batches of soils from the Savannah River site. Batches from the Oak Ridge and Hanford sites were not compared.

Results of precomplexed-type experiments in the Co(II)/EDTA/Savannah River soil system with the two batches of Savannah River soil are presented in Figure 15. These experiments were performed in an inert-atmosphere glove box 


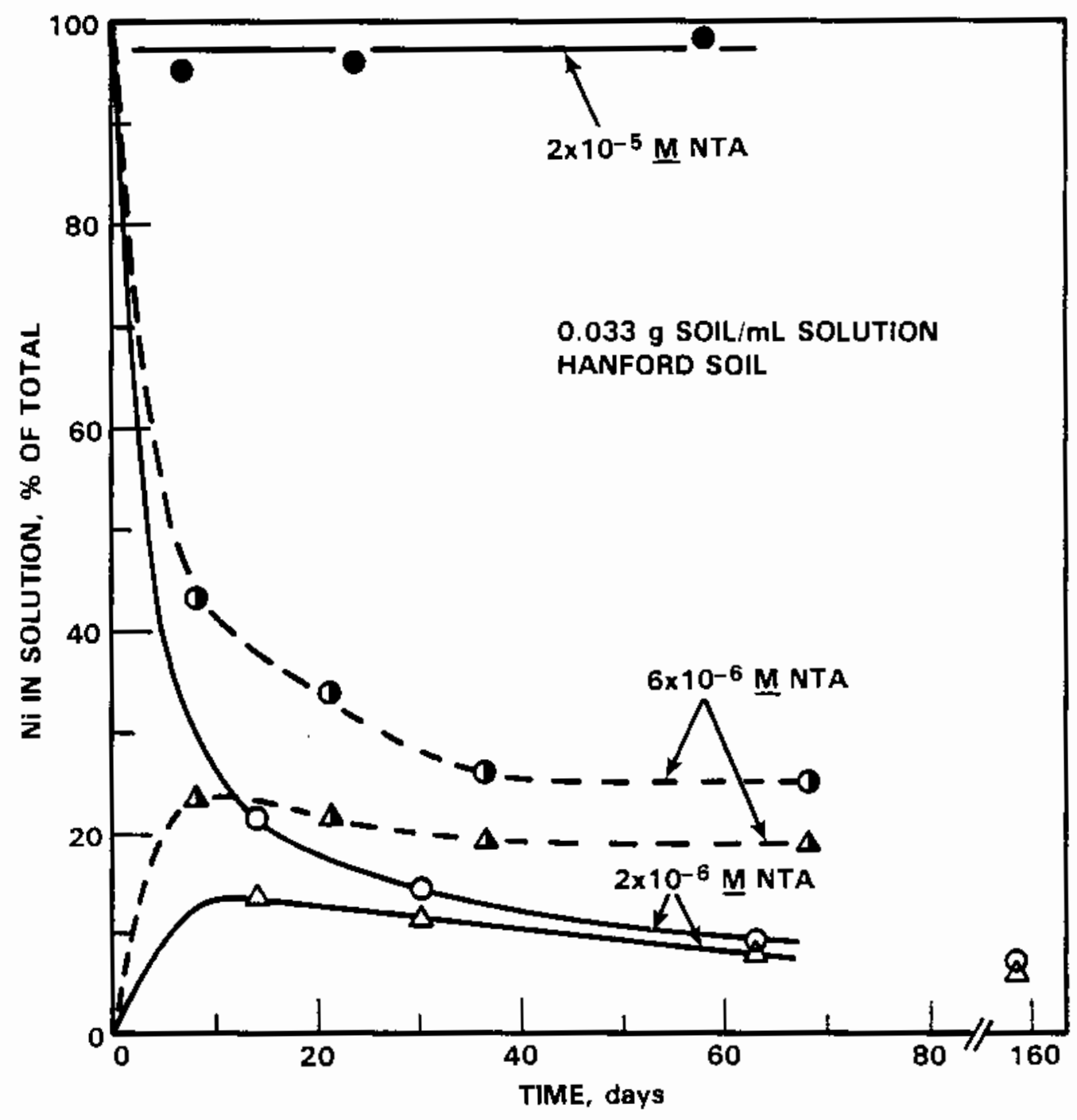

FIGURE 14. Comparison of Precomplexed and Presorbed Experiments from the Ni/NTA/Hanford SoiT System 


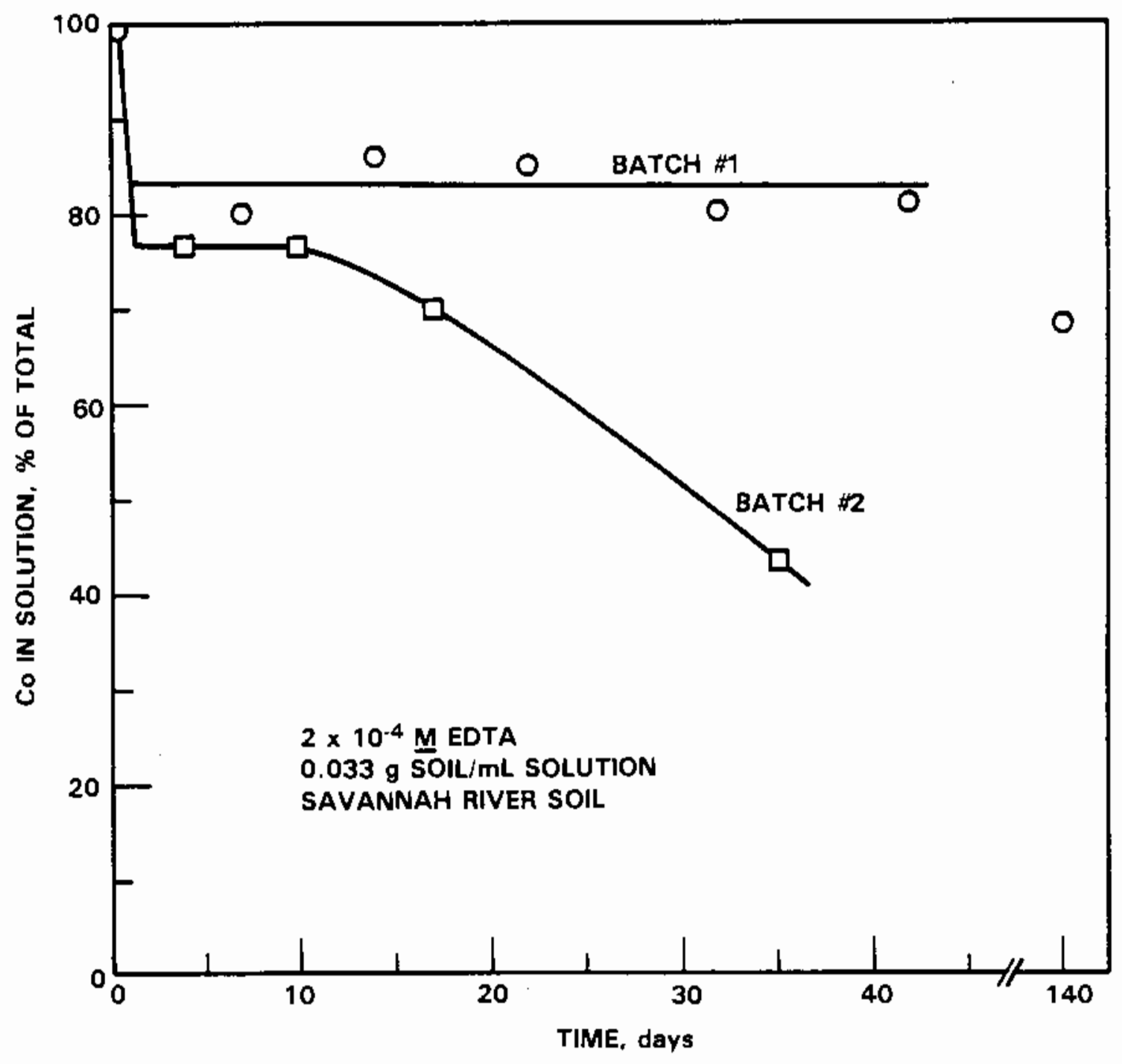

FIGURE 15. Effect of Soil Batch from Co(II)/EDTA/Savannah River Soi] System 
to prevent air oxidation of Co(II) to Co(III), which is known to occur in the presence of complexants.

Different behaviors were obtained with the two batches of Savannah River soil. The rapid initial sorption of $C_{0}$ is of comparable magnitude in the two cases, but the stabilities with time of the rapidly attained positions differ widely. With Batch 1 soil, a pseudo-equilibrium position appears to be stable for several months, but with Batch 2 soil the initially attained position is stabie only for a week or two. The initially attained sorption positions correspond to a $\mathrm{Kd}$ value of about $8 \mathrm{~mL} / \mathrm{g}\left(2 \times 10^{-4} \mathrm{M}\right.$ EDTA $)$. This value is 2 to 3 times lower than that discussed earlier in the Ni/EDTA/Savannah River soil system.

These results emphasize the fact that supposedly similar soil samples can give different radionuclide behaviors. Also, as was mentioned earlier, the leaching of elements from these two batches of Savannah River soil by EDTA solutions presented different pictures.

Ni/NTA/Oak Ridge Soil System

Some experiments were done in the Ni/NTA/Oak Ridge soil system, primarily to see if sorption of the complex itself is important here, as it was in the corresponding EDTA system. The results are confusing, but some of them do indicate that complex sorption may occur in this system as well.

The results of precomplexed-type experiments at three different NTA concentrations and presorption-type experiments at two of these NTA concentrations are shown in Figure 16. The results of the precomplexed-type experiments are similar to those obtained with EDTA (Figures 1 and 3); that is, a rapid decrease in Ni concentration followed by an extended period of apparent stability. The apparent Kd values calculated from these precomplexed-type experiments are $270 \mathrm{~mL} / \mathrm{g}$ at $1 \times 10^{-6} \mathrm{M} \mathrm{NTA}, 110 \mathrm{~mL} / \mathrm{g}$ at $1 \times 10^{-5} \mathrm{M} N \mathrm{~N}$, and $29 \mathrm{~mL} / \mathrm{g}$ at $1 \times 10^{-4} \mathrm{M}$ NTA. The dependence of apparent $\mathrm{Kd}$ on NTA concentration is less than that observed in the Eu/EDTA/Hanford soil system (Figure 2), which suggests sorption of the $\mathrm{Ni}-\mathrm{NTA}$ complex by Oak Ridge soil; but greater than that observed in the Ni/EDTA/0ak Ridge soil system, which suggests that sorption of the Ni-NTA complex is less important than sorption of the Ni-EDTA complex. 

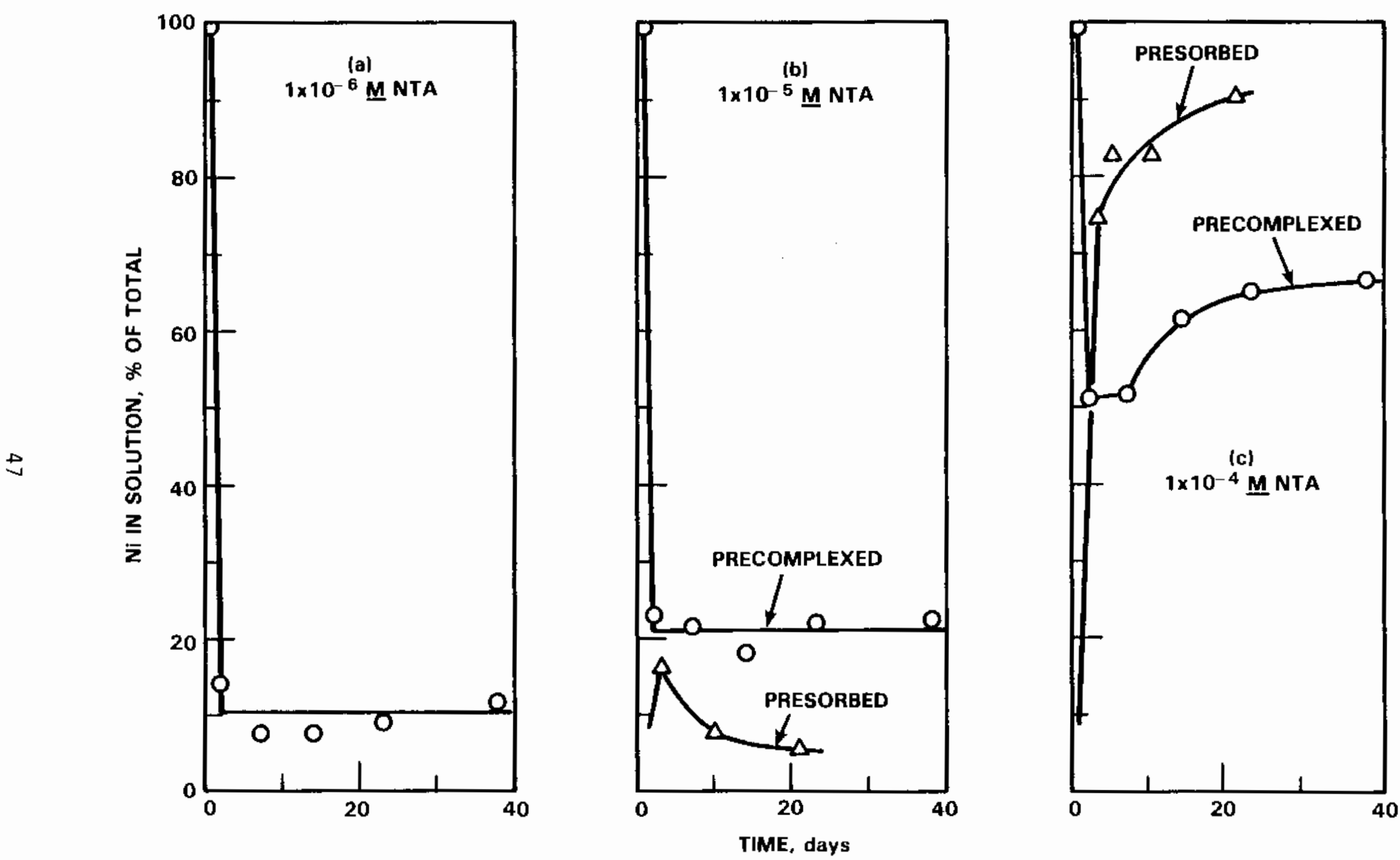

FIGURE 16. Results from Ni/NTA/Oak Ridge Soil System at Three Different NTA Concentrations 
The results of the presorbed-type experiments in the Ni/NTA/Oak Ridge soil system (Figures $16 \mathrm{~b}$ and $16 \mathrm{c}$ ) are not understood. With $1 \times 10^{-5} \mathrm{M}$ NTA, the $\mathrm{Ni}$ found in solution after a few days was in good agreenent with that found in the corresponding precomplexed-type experiment, but it then decreased markediy. With $1 \times 10^{-4}$ M NTA, the Ni found in solution after a few days was significantly greater than that found in the corresponding precomplexed-type experiment, and continued to increase with time. Obviously, more work is required to understand the behavior observed in this system.

Effect of $\mathrm{pH}$ on $\mathrm{Ni}$-EDTA Complex Dissociation Rate

The earlier work (Swanson 1982) showed that equilibrium was attained much more rapidly in Savannah River soil systems than in Hanford soil systems. One obvious difference in the two systems is the $\mathrm{pH}$, which is generally in the range of 5 to 6 with Savannah River soil and 8 to 9 with Hanford soil. Some experiments tested the effect of $\mathrm{pH}$ on the rate of dissociation of the Ni-EDTA complex to see if it could explain the different results with the two soils. An effect of $\mathrm{pH}$ was indeed observed, but only at values below those encountered with the soils, so this possible explanation for the difference in $\mathrm{Ni}$ behavior with the two soils does not appear to be valid.

These experiments were done by preparing a $5 \times 10^{-6} \underline{\mathrm{M}} \mathrm{Ni}+2 \times 10^{-5} \mathrm{M}$ EDTA stock solution, aging the stock solution for 7 days, then diluting severa 1 aliquots to $1 \times 10^{-8} \mathrm{M}$ EDTA at different $\mathrm{pH}$ values, and allowing the diluted aliquots to age for various time periods before portions were withdrawn for contacts with Hanford soil. The results of these experiments are given in Figure 17 .

The rate at which the Ni-EDTA complex was converted to a species which allowed the $\mathrm{Ni}$ to be sorbed during brief contact with Hanford soil increases markediy as the $\mathrm{pH}$ during aging decreases. However, the rate at $\mathrm{pH} 5.4$ is not much different than was observed in a companion experiment (discussed in the following section), where a diluted aliquot was immediately and continuously contacted with soil. This demonstrates that the pH effect is not important in the $\mathrm{pH}$ ranges developed in Hanford and Savannah River soil systems.

On decreasing the $\mathrm{pH}$ during aging from 5.4 to 3.9 , however, a marked difference in $\mathrm{Ni}$ behavior during soil contact was observed; as the time of aging increased, the fraction of the $N i$ that was sorbed during a subsequent 


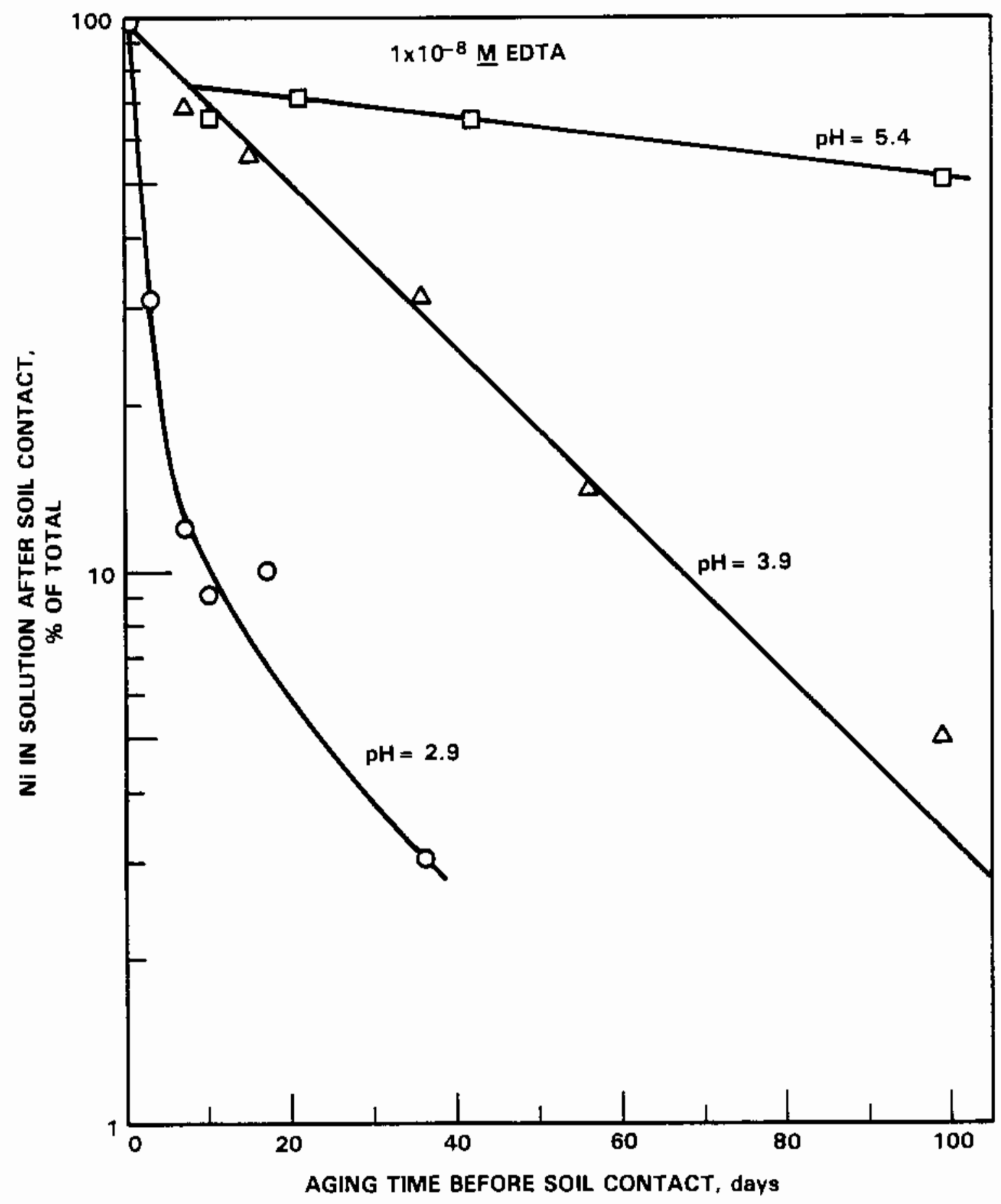

FIGURE 17. Effect of pH on Ni-EDTA Complex Dissociation Rate 
contact with soil increased. This effect was even more pronounced at a pH value of 2.9 during aging.

The data shown in Figure 17 were obtained after only 1 day of contact with Hanford soil; in some cases the contact time was extended by 1 week with no change in the $\mathrm{Ni}$ content of the solution. The pH values measured during these contacts were in the range normally encountered with Hanford soil. Ni/EDTA/Hanford Soil System

In the earlier work (Swanson 1981 and 1982) experiments were done in the $\mathrm{Ni} /$ EDTA/Hanford soil system in which $100 \%$ of the $\mathrm{Ni}$ remained in solution over a period of 1 year. Work done this year did not give the same result, aithough the rate at which $\mathrm{Ni}$ was sorbed by the soil was still quite slow. The reasons for this discrepancy are not known; they may involve the specifics of the preparation of the Ni-EDTA stock solutions, but this was not demonstrated.

An example of the type of results from this year's tests was obtained in conjunction with the experiments discussed in the preceding section. A diluted aliquot containing $1 \times 10^{-8}$ M EDTA of the same stock solution was contacted immediately and continuously with soil, for comparison with the cases shown in Figure 17 where other diluted aliquots were aged at different $\mathrm{pH}$ values before being contacted briefly with soil. In this case, $88 \%$ of the $\mathrm{Ni}$ remained in solution after 16 days and $69 \%$ remained after 49 days. As mentioned earlier, $100 \%$ of the $\mathrm{Ni}$ remained in solution for 1 year in earlier, simi lar experiments.

\section{Fe(II I) Addition Experiments}

The known strength of the Fe(III)-EDTA complex, and the markedly different behavior of the Ni-EDTA complex in the Hanford soil system than in the Fe-rich Savannah River and Oak Ridge soil systems, prompted examination of the effect of $\mathrm{Fe}$ (III) on the behavior of $\mathrm{Ni}$ in the Ni/EDTA/Hanford soil system. When the preformed Ni-EDTA complex was spiked (to $5 \times 10^{-9} \mathrm{M} N i$ ) into a solution containing $1 \times 10^{-5}$ M EDTA and $1 \times 10^{-5}$ M Fe(III) only 12 minutes before soil contact was begun, the behavior of the $\mathrm{Ni}$ was the same as in a simitar experiment in the absence of $\mathrm{Fe}$ (>90\% of the $\mathrm{Ni}$ remained in solution after 1 month). However, Fe(III) did have an effect in an experiment employing higher concentrations and a longer time before dilution and soil contact under 
otherwise identical conditions. Only $6 \%$ of the $\mathrm{Ni}$ remained in solution after 4 days when the preformed $\mathrm{Ni}$-EDTA complex was spiked (to $4 \times 10^{-7} \mathrm{M} \mathrm{Ni}$ ) into a solution containing $1 \times 10^{-3} \underline{M}$ EDTA and $1.5 \times 10^{-3} M \mathrm{Me}$ (III) 3 days before the solution was diluted $100-$ fold and soil contact was begun.

These data show little effect of $\mathrm{Fe}$ (III) on the behavior of the Ni-EDTA complex during contact with Hanford soil, but that a large effect can occur prior to soil contact. This effect is presumably the dissociation of the $\mathrm{Ni}$ EDTA complex, caused by preferential complexing of the EDTA by the Fe(III). These data indicate that this dissociation does not occur immediately but does occur rapidly enough under some conditions that the addition of Fe(III) to EDTA-containing waste solutions could make the wastes less hazardous from a radionuclide mobility standpoint. 



\section{REFERENCES}

Basolo, F, and R. G. Pearson. 1967. Mechanisms of Inorganic Reactions: A Study of Metal Complexes in Solution. 2nd Edition, pp. 221-222, John Wiley and Sons, New York.

Davis, J. A. and J. O. Leckie. 1978. "Effect of Adsorbed Complexing Ligands on Trace Metal Uptake by Hydrous 0xides." Environmental Science and Technology 12:1309-1315.

Dean, J. A., Ed. 1973. Lange's Handbook of Chemistry. 11th Edition, McGrawHi11, New York.

Gee, G. W., and A. C. Campbe11. 1980. Monitoring and Physical Characterization of Unsaturated Zone Transport-Laboratory Analysis. PNL-3304, Pacific Northwest Laboratory, Richland, Washington.

Lahav, N. and M. Hochberg. 1975. "Kinetics of Fixation of Iron and Zinc Applied as FeEDTA, FeHDDHA, and ZnEDTA in the Soil." Soil Science Society of America Proceedings 39:55-58.

Means, J. L. 1982. The Importance of Organic Compounds in Ground water as Radionuclide-Mobilizing Agents. ONWI-348, Battelle Columbus Laboratories, Columbus, ohio.

Means, J. L. and C. A. Alexander. 1981. "The Envi ronmental Biogeochemistry of Chelating Agents and Recommendations for the Disposal of Chelated Radioactive Wastes." Nuclear and Chemical Waste Management 2:183-196.

Means, J. L., D. A. Crerar, and J. 0. Duguid. 1976. Chemical Mechanisms of ${ }^{60}$ Co Transport in Ground Water from Intermediate-Level Liquid Waste Trench 7: Progress Report for Period Ending June 30, 1975. ORNL-TM-5348, 0ak Ridge National Laboratory, Oak Ridge, Tennessee.

Means, J. L., D. A. Crerar, and J. 0. Duguid. 1978. "Migration of Radioactive Wastes: Radionuclide Mobilization by Complexing Agents." Science 200:1477-1481.

Norve11, W. A. 1972. "Equilibria of Metal Chelates in Soil Solution." In Micronutrients in Agriculture. R. C. Dinauer, Managing Editor, Soil Science Society of America, Inc., Madison, Wisconsin.

Norve11, W. A. and W. L. Lindsay. 1982. "Estimation of the Concentration of $\mathrm{Fe}^{3+}$ and the $\left(\mathrm{Fe}^{3+}\right)(\mathrm{OH})^{3}$ Ion Product from Equilibria of EDTA in Soil." Soil Sciience Society of America Proceedings 39:710-715.

Sibley, T. H., A. L. Sanchez, and W. R. Schell. 1981. Distribution Coefficients for Radionuclides in Aquatic Envi ronments, Adsorption Studies of Cobalt. NUREG/CR-1852, University of Washington, Seattle, Washington.

Swanson, 3. L. 1981, Effect of Organic Complexants on the Mobility of LowLevel Waste Radionuclides in Soils: Status Report. PNL-3927, Pacific Northwest Laboratory, Richland, Washington. 
Swanson, J. L. 1982. Effect of Organic Complexants on the Mobility of Nickel and Cobalt in Soils: Status Report. PNL-4389, Pacific Northwest Laboratory, Richland, Washington.

Vaughan, N. D., C. S. Ha ase, D. D. Huff, S. Y. Lee, and E. C. Walls. 1982. Field Demonstration of Improved Shallow Land Burial Practices for Low-Level Radioactive Solid Wastes: Preliminary Site Characterization and Progress Report. ORNL/TM-8477, Oak Ridge National Laboratory, Oak Ridge, Tennessee.

Weiss, A. J. and P. Columbo. 1980. Evaluation of Isotope Migration-Land Burial, Water Chemistry at Commercially Operated Low-Level Radioactive Waste Disposal Sites, Quarterly Progress Report, October-December 1979. NUREG/CR1325, Brookhaven National Laboratory, Upton, New York. 


\section{ACKNOWLEDGMENTS}

The experiments were performed and the radionuclide distribution measurements were made by $A$. D. Peoples. The ICP analyses were performed under the direction of F. T. Hara and $A$. W. Lautensleger, and the gas chromatographic analyses under the direction of A. P. Toste. C. L. Matsuzaki assisted with the ion chromatographic analyses. Soil from the Oak Ridge site was provided by N. H. Cutshall of Oak Ridge National Laboratory.

Thanks are due to many people for informative discussions and helpful suggestions. Among those who contributed in this regard are J. L. Ryan, H. H. Van Tuy1, D. Rai, E. A. Jenne, and R. E. Wildung of PNL and L. J. Mezga of ORNL.

The cooperation of many people from PNL and the commercial vendors made possible our work with the commercial decontamination solutions; this help is gratefully acknowledged.

The report was typed by L. D. Maki and edited by S. E. King. 


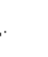




\section{APPENDIX}

DETAILED DATA ON THE LEACHING OF METAL IONS FROM SOILS 


\section{APPENDIX}

DETAILED DATA ON THE LEACHING OF METAL IONS FROM SOILS

This appendix contains the detailed results of the work done this year on the leaching of metal ions from soils. Some highlights of these results were discussed in the text; these detailed results are presented for completeness. The first three tabies contain solutions under a variety of conditions. The fourth table contains the resuits of leaching 0ak Ridge soils with NTA solutions. 
TABLE A.1. Metal Ions Leached from Hanford Soil ${ }^{(a)}$ by EDTA

\begin{tabular}{|c|c|c|c|c|c|c|c|c|c|c|c|c|}
\hline \multirow[b]{2}{*}{$\mathrm{Na}, 2 \mathrm{ED} T \mathrm{~A}, \mathrm{M}$} & \multirow{2}{*}{$\begin{array}{l}\text { Time, } \\
\text { Days }\end{array}$} & \multirow{2}{*}{$\begin{array}{l}\text { g Soil/ } \\
\text { mL Solution }(b)\end{array}$} & \multirow[b]{2}{*}{$\mathrm{pH}$} & \multicolumn{9}{|c|}{ Found in Filtered $(c)$ Leachate, $M \times 10^{4}$} \\
\hline & & & & $\mathrm{Na}$ & $K$ & $\mathrm{Mg}$ & $\mathrm{ca}$ & $2 \pi$ & $M n$ & $A 1$ & $\mathrm{Fe}$ & $S i$ \\
\hline- & $\begin{array}{c}2 \\
14 \\
44 \\
44(d) \\
206(d)\end{array}$ & $\begin{array}{l}0.033 \\
0.037 \\
0.042 \\
0.042 \\
0.061\end{array}$ & $\begin{array}{l}9.13 \\
8.42\end{array}$ & $\begin{array}{l}8.4 \\
9.0 \\
8.2 \\
7.2 \\
8.7\end{array}$ & $\begin{array}{l}0.46 \\
0.88 \\
0.72 \\
0.59 \\
1.1\end{array}$ & $\begin{array}{l}0.17 \\
0.49 \\
0.77 \\
0.80 \\
1.3\end{array}$ & $\begin{array}{l}0.33 \\
1.0 \\
1.6 \\
1.6 \\
2.8\end{array}$ & $\begin{array}{l}0.03 \\
0.09 \\
0.26 \\
0.39 \\
0.40\end{array}$ & $\begin{array}{l}-- \\
-- \\
0.006 \\
0.007 \\
--\end{array}$ & $\begin{array}{l}0.02 \\
-- \\
-- \\
-- \\
--\end{array}$ & $\begin{array}{l}-- \\
-- \\
-- \\
0.02 \\
0.02\end{array}$ & $\begin{array}{l}3.8 \\
4.2 \\
4.5 \\
4.4 \\
4.0\end{array}$ \\
\hline $5 \times 10^{-5}$ & $\begin{array}{r}3 \\
5 \\
13 \\
21 \\
34 \\
66\end{array}$ & $\begin{array}{l}0.033 \\
0.037 \\
0.042 \\
0.048 \\
0.056 \\
0.067\end{array}$ & $\begin{array}{l}9.20 \\
9.03 \\
8.74 \\
8.37 \\
8.32 \\
8.14\end{array}$ & $\begin{array}{c}7.4 \\
8.5 \\
8.5 \\
10 \\
10 \\
8.7\end{array}$ & $\begin{array}{l}0.49 \\
0.56 \\
0.49 \\
0.59 \\
0.67 \\
0.90\end{array}$ & $\begin{array}{l}0.31 \\
0.35 \\
0.65 \\
0.83 \\
1.0 \\
1.4\end{array}$ & $\begin{array}{l}1.1 \\
1.1 \\
1.9 \\
2.2 \\
2.6 \\
3.6\end{array}$ & $\begin{array}{l}0.26 \\
0.34 \\
0.42 \\
0.60 \\
0.55 \\
0.34\end{array}$ & $\begin{array}{l}0.003 \\
0.006 \\
0.020 \\
0.026 \\
0.018 \\
0.008\end{array}$ & $\begin{array}{l}0.03 \\
0.02 \\
0.03 \\
-- \\
-- \\
--\end{array}$ & $\begin{array}{l}= \\
-- \\
0.005 \\
0.003 \\
0.002 \\
0.011\end{array}$ & $\begin{array}{l}3.4 \\
3.6 \\
4.0 \\
4.6 \\
4.7 \\
4.9\end{array}$ \\
\hline
\end{tabular}

\footnotetext{
(a) 150-500 $\mu \mathrm{m}$ sieved portion,

(b) Ratio varies as solution is removed for analysis.

(c) Itsing 2-nm membrane fllter cones.

(d) Sample actdiffed after filtration.
} 
TABLE A.2. Metal Ions Leached from Savannah River Soil (a) by EDTA

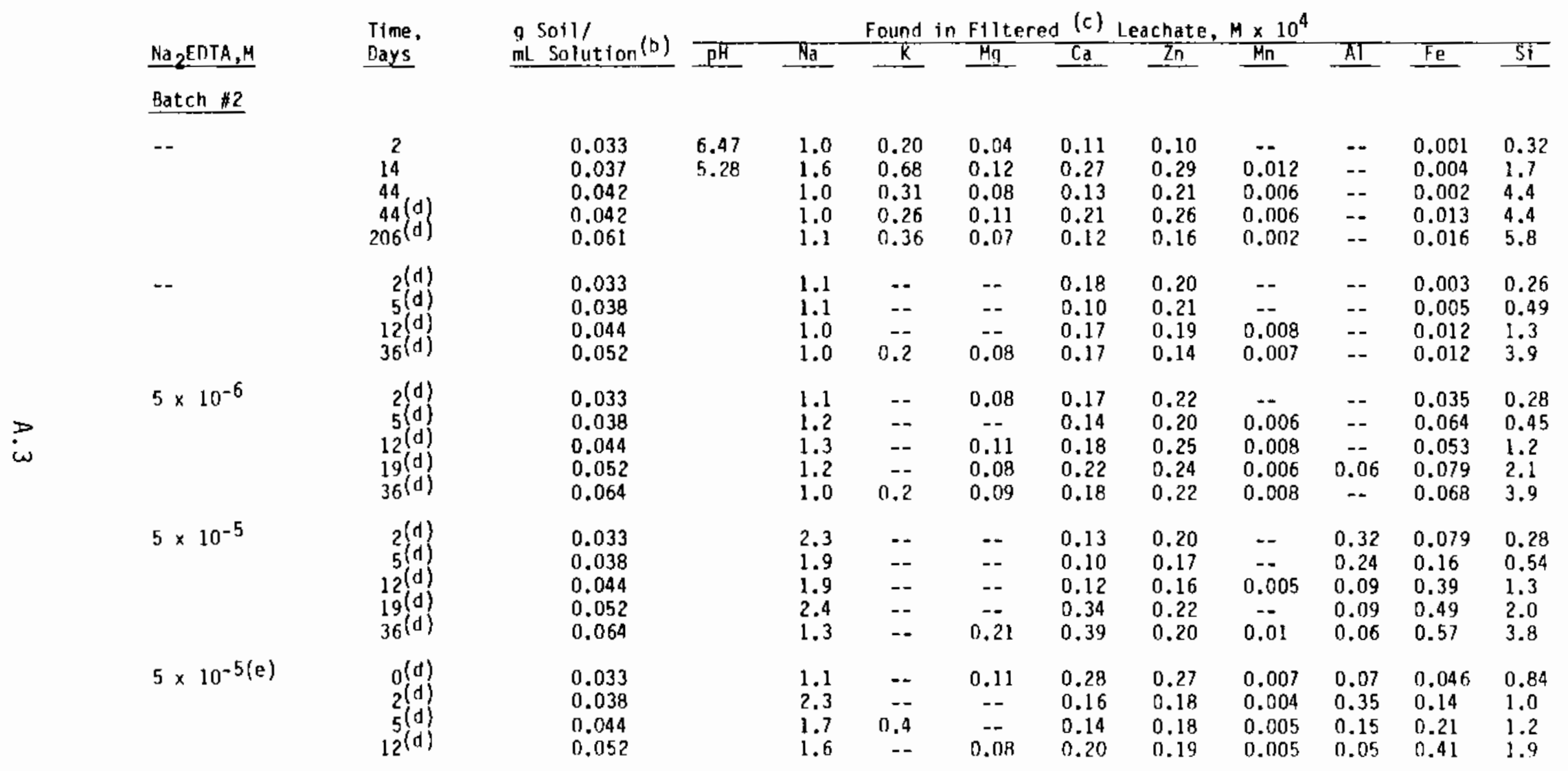

(a) 150-500 $\mu \mathrm{m}$ steved portion.

(b) Ratio varies as solution is removed for analysis.

(c) Using $2-\mathrm{nm}$ membrane filter cones.

(d) Sample acidified after filtration.

(e) Soil contacted with water for 15 days before EDTA was adided. 
TABLE A.2. (cont.)

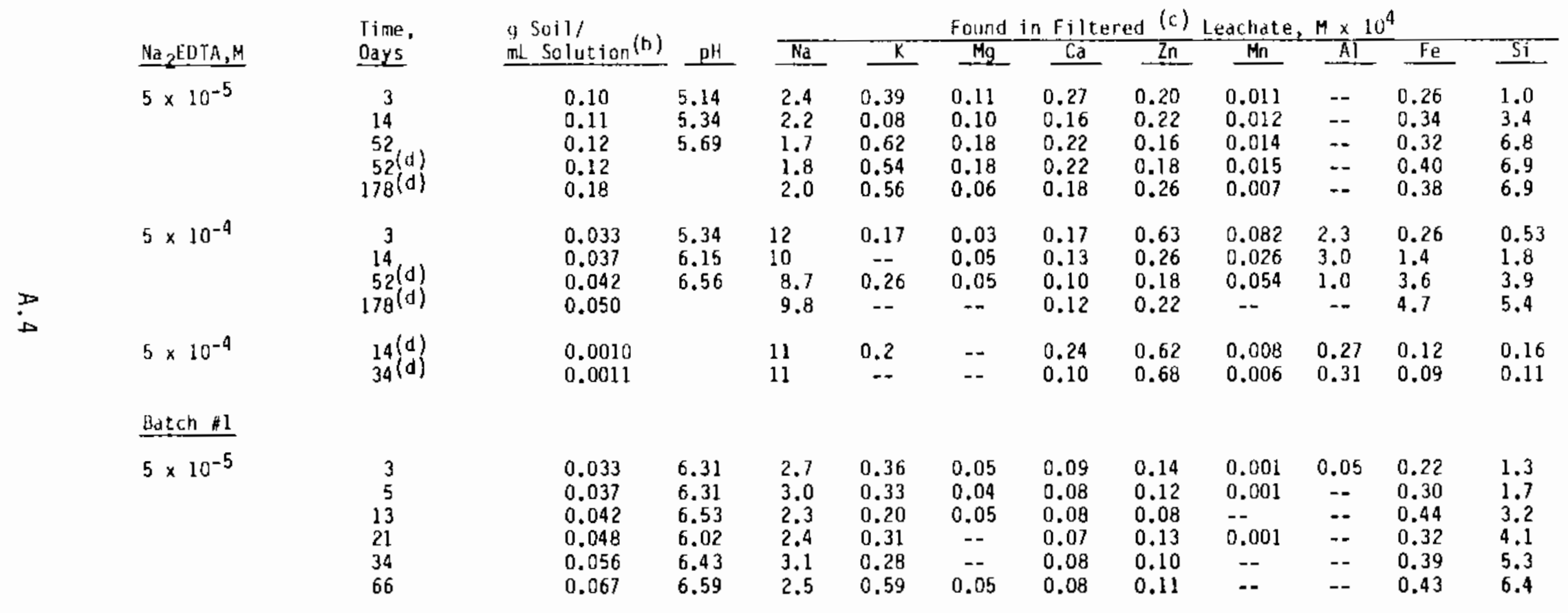

\footnotetext{
(d) 150-500 $\mu$ rll steved portion.

(b) Ratlo varles as solution is removed for analysis.

(c) Using 2-nm membrane filter cones.

(d) Sample acidified after filtration.

(e) Soil contacted with water for 15 days before EDIA was added.
} 
TABLE A.3. Metal Ions Leached from Oak Ridge Soif (a) by EDTA

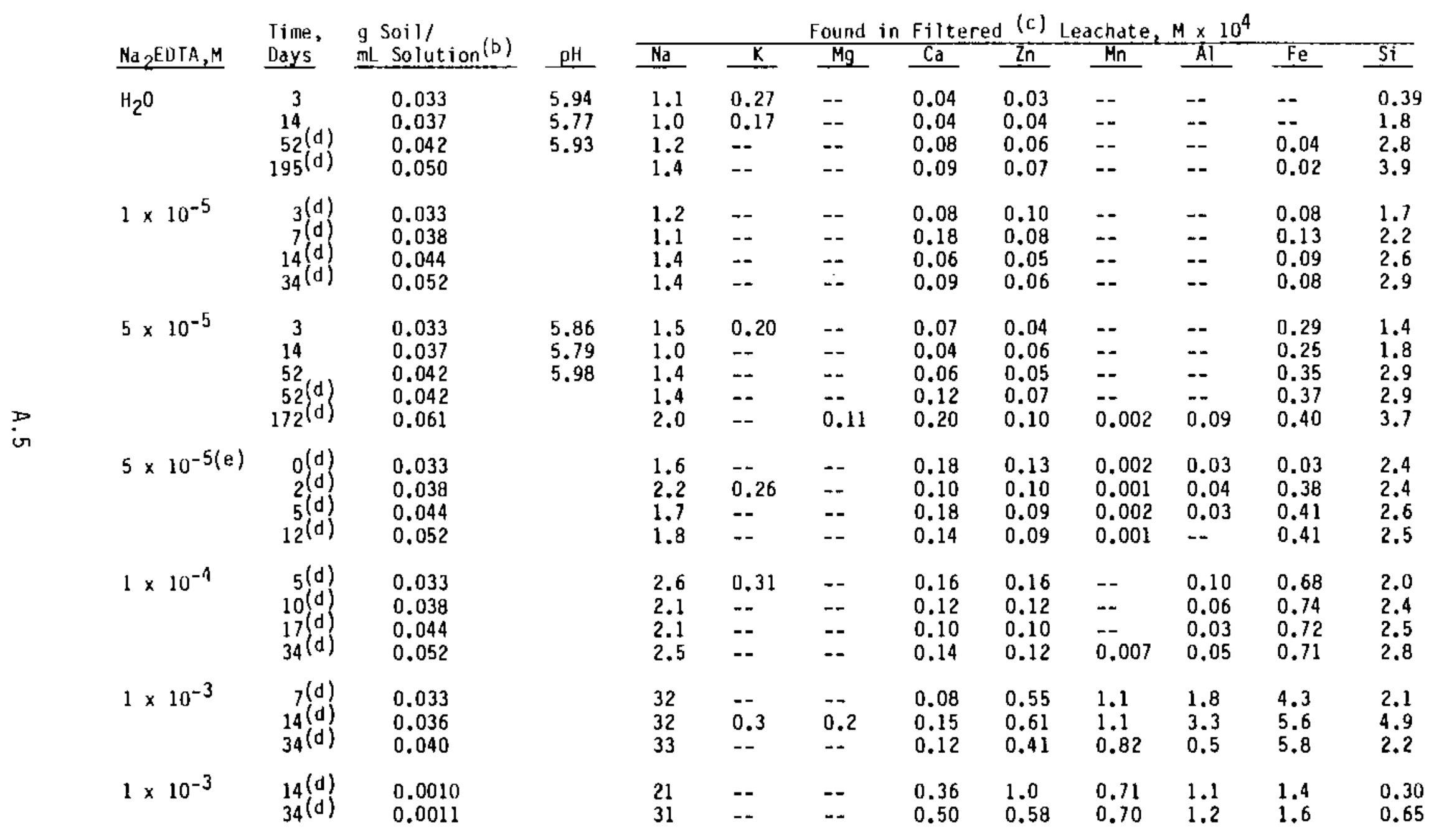

(a) 150-500 $\mu \mathrm{m}$ sieved portion.

(b) Ratio varies as solution is relloved for analysis.

c) Using 2-nm membrane filter cones.

d) Sample actifified after filtration.

(e) Soil contacted with water for 15 days before E0TA was added. 
TABLE A.4. Metal Ions Leached from Oak Ridge Soil(a) by NTA

ơ

\begin{tabular}{|c|c|c|c|c|c|c|c|c|c|c|c|c|}
\hline \multirow[b]{2}{*}{ NIA, $M$} & \multirow{2}{*}{$\begin{array}{l}\text { Time, } \\
\text { Days }\end{array}$} & \multirow{2}{*}{$\begin{array}{l}\text { y Soil/ } \\
\text { mL Solution(h) }\end{array}$} & \multirow[b]{2}{*}{$\mathrm{pH}$} & \multicolumn{9}{|c|}{ Found in Filtered (c) Leachate, $M \times 10^{4}$} \\
\hline & & & & $\mathrm{Na}$ & $k$ & $\mathrm{Mg}$ & $\mathrm{Ca}$ & Zn & $M_{n}$ & AT & $\mathrm{Fe}$ & ST \\
\hline $1 \times 10^{-5}$ & $\begin{array}{r}3(d) \\
7(d) \\
14(d) \\
34(d)\end{array}$ & $\begin{array}{l}0.033 \\
0.038 \\
0.044 \\
0.052\end{array}$ & & $\begin{array}{l}1.2 \\
1.1 \\
1.6 \\
1.5\end{array}$ & $\begin{array}{l}-- \\
-- \\
--\end{array}$ & $\begin{array}{l}-- \\
-- \\
--\end{array}$ & $\begin{array}{l}0.08 \\
0.04 \\
0.05 \\
0.09\end{array}$ & $\begin{array}{l}0.12 \\
0.07 \\
0.06 \\
0.08\end{array}$ & $\begin{array}{l}-- \\
-- \\
-- \\
--\end{array}$ & $\begin{array}{l}0.04 \\
0.04 \\
0.03 \\
0.09\end{array}$ & $\begin{array}{l}0.04 \\
0.03 \\
0.02 \\
0.05\end{array}$ & $\begin{array}{l}1.7 \\
2.1 \\
2.4 \\
2.9\end{array}$ \\
\hline $1 \times 10^{-4}$ & $\begin{array}{r}5^{(d)} \\
10^{(d)} \\
17(d) \\
34(d)\end{array}$ & $\begin{array}{l}0.033 \\
0.038 \\
0.044 \\
0.052\end{array}$ & & $\begin{array}{l}2.1 \\
1.4 \\
1.1 \\
2.0\end{array}$ & $\begin{array}{l}0.31 \\
-- \\
0.29 \\
--\end{array}$ & $\begin{array}{l}0.60 \\
0.46 \\
0.18 \\
0.07\end{array}$ & $\begin{array}{l}0.50 \\
0.38 \\
0.20 \\
0.20\end{array}$ & $\begin{array}{l}0.52 \\
0.44 \\
0.26 \\
0.26\end{array}$ & $\begin{array}{l}0.36 \\
0.31 \\
0.09 \\
0.04\end{array}$ & $\begin{array}{l}1.9 \\
1.7 \\
1.2 \\
1.0\end{array}$ & $\begin{array}{l}0.68 \\
0.65 \\
0.70 \\
0.59\end{array}$ & $\begin{array}{l}2.5 \\
3.0 \\
3.0 \\
3.3\end{array}$ \\
\hline $1 \times 10^{-3}$ & $\begin{array}{r}7 \text { (d) } \\
14 \text { (d) } \\
344^{(d)}\end{array}$ & $\begin{array}{l}0.033 \\
0.036 \\
0.040\end{array}$ & & $\begin{array}{l}2.2 \\
2.2 \\
2.6\end{array}$ & $\begin{array}{l}0.46 \\
0.46 \\
0.54\end{array}$ & $\begin{array}{l}4.7 \\
4.9 \\
5.0\end{array}$ & $\begin{array}{l}2.8 \\
2.8 \\
3.2\end{array}$ & $\begin{array}{l}0.84 \\
0.92 \\
1.1\end{array}$ & $\begin{array}{l}2.2 \\
2.2 \\
2.6\end{array}$ & $\begin{array}{l}32 \\
32 \\
30\end{array}$ & $\begin{array}{l}34 \\
34 \\
33\end{array}$ & $\begin{array}{l}12 \\
14 \\
16\end{array}$ \\
\hline
\end{tabular}

(a) 150-500 $\mu \mathrm{m}$ sieved portion.

(b) Ratio varies as solution is renoved for analysis.

(c) Using 2-nm membrane filter cones.

(d) Sample acidified after filtration. 
PNL -4796

UC $-70 \mathrm{~B}$

\section{DISTRIBUTION}

No. of

Copies

OFFSITE

27 DOE Technical Information Center

2 Division of Storage and Treatment

Projects

NE-25 (GTN)

U. S. Department of Energy

Washington, DC 20545

ATTN: J. A. Coleman

E. A. Jordan

2 R\&D and Byproducts Division

DP-123 (GTN)

U. S. Department of Energy

Washington, DC 20545

ATTN: T. C. Chee

J. J. Jicha

J. E. Dieckhoner, Acting Director Operations and Traffic Division OP-122 (GTN)

U. S. Department of Energy

Washington, DC 20545

G. K. Derte1, Director

Office of Defense Waste and

Byproducts Management

DP-12 (GTN)

$\mathrm{U}$. S. Department of Energy

Washington, DC 20545

4 Nuclear Regulatory Commission

Washington, DC 20555

ATTN: D. H. Alexander

E. D'Donnel ?

T. C. Johnson

R. J. Starmer

2 Nevada Operations Office

U. S. Department of Energy

P. 0. Box 14100

Las Vegas, NV 89114

ATTN: R. Boland

B. W. Church
No of

Copies

3 Idaho Operations Office

U. S. Department of Energy

550 Second Street

Idaho Falls, ID 83401

ATTN: M. J. Barainca

C. P. Gertz

J. B. Whitsett

2 Savannah River Operations office

U. S. Department of Energy

P. 0. Box A

Ajken, SC 29801

ATTN: B. Lawless

H. Saucier

Len Lanni

San Francisco Operations Office

U. S. Department of Energy

1333 Broadway

0akland, CA 94612

2 Oak Ridge Operations Office

U. S. Department of Energy

P. 0. Box E

Oak Ridge, TN 37830

ATTN: D. E. Large

C. L. Mathews

2 Albuquerque Operations Office

U. S. Department of Energy

P. 0. Box 5400

Albuquerque, NM 87115

ATTN: R. Y. Lowrey

D. M. Lund

2 Chicago Operations Office

U. S. Department of Energy

980D South Cass Avenue

Argonne, IL 60439

ATTN: S. Mann

F. Gorup

Office of Radiation Programs

Technological Assessment Division (AW-559)

Envi ronmental Protection Agency
Washington, DC 20460 
No of

Copies

C. S. Abrams, Manager of Radiol. Eng. Argonne National Laboratory - West P. 0. Box 2528

Idaho Falls, ID 83401

R. E. Anderson

Goodyear Atomic

P. 0. Box 628

Piketon, $\mathrm{OH} 45661$

M. W. Boback, Director

Health and Safety Division

P. 0. Box 39158

Cincinnati, $\mathrm{OH} 45239$

Jack G. Couch

Fermi National Accelerator Laboratory

P. 0. Box 500

Batavia, IL 60510

T. Harvey

Mail Stop L-262

Lawrence Livermore National

Laboratory

P. 0. Box 8D8

Livermore, CA 94550

E. W. Kendall

Waste Management Project Manager

REEC0

P. 0. Box 642

Mercury, NV 89023

J. McMenamin

Mason and Hanger - Silas Mason Co.

Pantex Plant

P. 0. Box 30020

Amarillo, TX 79177

C. E. Wickland

Manager, Waste Operations

Rockwell International

Rocky Flats Plant

P. 0. Box 464

Golden, C0 80401

J. Howard Kittel, Manager

Office of Waste Management Programs

Argonne National Laboratory

9700 S. Cass Avenue, Bldg. 205

Argonne, IL 60439
No. of

Copies

Peter Colombo, Group Leader

Nuclear Waste Research

Brookhaven National Laboratory

Building 701

Upton, NY 11973

2 EG\&G Idaho, Inc.

P. 0 . Box 1625

Idaho Falls, ID 83415

ATTN: R. H. Beers

G. B. Levin

2 Los Alamos National Laboratory

P. 0. Box 1663

Los Alamos, NM 87545

ATTN: D. T. Oakley

U. G. Steger

Ralph R. Jaeger, Manager

Nuclear Waste Technology

Monsanto Research Corporation

P. 0. Box 32

Miamisburg, $\mathrm{OH} 45342$

5 Oak Ridge National Laboratory

P. 0 . Box $X$

Oak Ridge, TN 37830

ATTN: N. H. Cutshal1

L. J. Mezga

T. H. Row

L. E. Stratton

Central Research Library

2 Savannah River Laboratory

P. 0. Box A

Aiken, SC 29801

ATTN: E. L. Albenesius

J. Wiley

J. J. Blakeslee, Program Manager

Nuclear Waste Processing

Rockwell International

P. 0. Box 464

Golden, C0 80401

Jack Fischer

Low-Level Radioactive Waste Program

U. S. Geological Survey

Water Resources Division

12201 Sunrise Valley Drive

Reston, VA 22092 
No of

Copies

2 Battelle Memorial Institute

$505 \mathrm{King}$ Avenue

Columbus, $\mathrm{OH} 43201$

ATTN: Beverly Rawles

Research Library

Robert Williams

Electric Power Research Institute

$3412 \mathrm{Hill}$ view Avenue

Palo Alto, CA 94304

William F. Holcomb

National Institutes of Health

Radiation Safety Branch

Building 21

Bethesda, MD 20205

\section{ONSITE}

3 DOE Richland Operations of fice

P. F. X. Dunigan, Jr.

G. Orten

J. J. Schreiber

3 Rockwell Hanford Operations

J. F. Albaugh

J. L. Deichman

H. E. McGuire

UNC United Nuclear Industries

F. H. Bouse, Document Control

Westinghouse Hanford Company

R. E. Lerch

56 Pacific Northwest Laboratory

R. P. Allen

L. L. Ames

L. A. Bray

R. L. Brodzinski

L. L. Burger

T. D. Chikalla

J. A. Franz

T. R. Garland

G. W. Gee

J. H. Jarrett
E. A. Jenne

T. L. Jones

S. E. King

L. J. Kirby

M. R. Kreiter

J. M. Latkovich

J. L. MCEl roy

L. D. Maki

R. E. Nightingale

A. D. Peoples

R. H. Perkins

D. Rai

D. E. Robertson

R. U. Serne

S. L. Stein

J. L. Swanson (20)

A. P. Toste

H. H. Van Tuyl

E. J. Wheelwright

R. E. Wilding

Technical Information (5)

Publishing Coordination (2) 


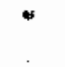

$\rightarrow$

,

4 